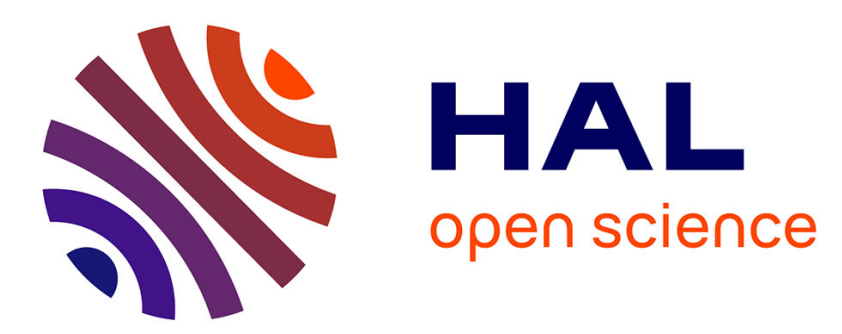

\title{
Les facteurs de production du système protéolytique de Penicillium caseicolum
}

\author{
J. Lenoir, A. Glenza, J. L. Bergere, O. Cerf, C. Choisy, M. Desmazeaud, J. \\ Hermier, B. Auberger, Michèle Schmidt
}

\section{To cite this version:}

J. Lenoir, A. Glenza, J. L. Bergere, O. Cerf, C. Choisy, et al.. Les facteurs de production du système protéolytique de Penicillium caseicolum. Le Lait, 1973, 53 (525_526), pp.246-279. hal-00928622

\section{HAL Id: hal-00928622 \\ https://hal.science/hal-00928622}

Submitted on 1 Jan 1973

HAL is a multi-disciplinary open access archive for the deposit and dissemination of scientific research documents, whether they are published or not. The documents may come from teaching and research institutions in France or abroad, or from public or private research centers.
L'archive ouverte pluridisciplinaire HAL, est destinée au dépôt et à la diffusion de documents scientifiques de niveau recherche, publiés ou non, émanant des établissements d'enseignement et de recherche français ou étrangers, des laboratoires publics ou privés. 


\title{
Les facteurs de production du système protéolytique de Penicillium caseicolum ${ }^{(1)}$
}

\author{
par \\ J. LENOIR*, A. GLENZA**, J. L. BERGERE**, O. CERF**, \\ C. CHOISY*, M. DESMAZEAUD ${ }^{* *}$ et J. HERMIER ** \\ avec la collaboration technique de B. AUBERGER* \\ et Michèle SCHMIDT* \\ * Laboratoire de Recherche de la Chaire de Technologie (I.N.R.A.) \\ Institut National Agronomique Paris-Grignon - 78850 Thiverval-Grignon \\ ** Station Centrale de Recherche Laitière (I.N.R.A.) - 78350 Jouy-en-Josas
}

\section{INTRODUCTION}

Actuellement, presque tous les fromages à pâte molle et à moisissures superficielles sont recouverts du feutrage mycélien blanc formé par $P$. caseicolum Bainier (syn. $P$. candidum Link). Cette moisissure joue un rôle essentiel dans l'affinage des pâtes; elle consomme l'acide lactique et ainsi désacidifie le milieu; en outre elle libère des enzymes qui participent activement à l'évolution des constituants et au développement des caractères organoleptiques des fromages.

L'activité protéolytique de $P$. caseicolum a été observée et étudiée par plusieurs chercheurs, notamment Maze (1905), Thom (1906, 1909), Sansonnetti (1930), Dolezalek (1956), Tsugo et Matsuoka (1963), et certains d'entre nous ont récemment précisé, sur une collection d'une centaine de souches de diverses origines, l'aptitude de l'espèce à la production de protéase (Lenoir et Choisy, 1971). Ce travail a mis en évidence une assez grande homogénéité de la population. Lorsqu'elles sont placées dans les mêmes conditions de culture, les souches de $P$. caseicolum produisent en effet des quantités d'enzymes qui sont relativement peu différentes. En revanche, les essais préliminaires, visant à la mise au point de conditions expérimentales propres à l'estimation de l'aptitude des souches à la protéolyse, ont révélé des variations notables dans la production d'enzymes, variations en fonction de la composition du milieu de culture, du pH et de la tempéra-

(1) Travail réalisé dans le cadre d'un contrat de la Délégation Générale à la Recherche Scientifique et Technique. Contrat $\mathrm{n}^{\circ} 6701037$ sur l'emploi d'enzymes d'origine microbienne dans l'affinage des fromages. 
ture notamment. Une étude des facteurs qui contrôlent la synthèse des protéases par $P$. caseicolum est donc d'un grand intérêt, tant pour l'étude de la maturation des pâtes molles que dans la perspective d'une production industrielle d'enzymes en vue de leur emploi dans l'affinage des fromages (Lenoir et al., 1971).

\section{I. - MATERIEL ET METHODES}

\subsection{Organismes et inoculum}

Les souches essayées, P1, PL21, PC12, PN14, proviennent de la collection du Laboratoire de Technologie de l'I.N.A. Paris-Grignon. La conservation des souches a été assurée par culture sur milieu Czapek-trypticase $\mathrm{A}$ gélosé à 15 p. 1000. Après incubation de $15 \mathrm{j}$ à $20^{\circ} \mathrm{C}$ les cultures sont placées en chambre froide à $+5^{\circ} \mathrm{C}$ et repiquées régulièrement tous les 2 mois, La suspension de spores utilisée comme inoculum dans les essais de croissance et de production est préparée selon la technique décrite antérieurement (Lenoir et Choisy, 1971) : ensemencement sur pâte seigle-blé, incubation $10 \mathrm{j}$ à $18-20^{\circ} \mathrm{C}$, récolte des spores par agitation en présence de Ringer au 1/4, ajustement de la richesse de la suspension de spores après dénombrement à l'aide d'une cellule de Petroff-Hauser ou par mesure photométrique. Une bonne production de spores a pu également être obtenue sur milieu Potato Dextrose Agar (Difco). Dans la plupart des essais l'inoculum est ajouté à raison de $1 \mathrm{ml}$ pour $40 \mathrm{ml}$ de milieu et le taux d'ensemencement est de 10000 spores par $\mathrm{ml}$.

\subsection{Milieu de culture}

Le milieu de base utilisé est le milieu Czapek-trypticase A dérivé du milieu de Czapek-Dox (Thom et Raper, 1945) par apport de glucose, supplémentation en oligo-éléments, addition d'un tampon phosphate et remplacement du nitrate de sodium par une peptone trypsique de caséine (trypticase Mérieux). Sa composition est la suivante : glucose, $10 \mathrm{~g}$; trypticase, $10 \mathrm{~g}$; $\mathrm{MgSO}_{4}, 7 \mathrm{H}_{2} \mathrm{O}, 0,5 \mathrm{~g}$; $\mathrm{FeSO}_{4}, 7 \mathrm{H}_{2} \mathrm{O}, 0,01 \mathrm{~g}$; solution d'oligo-éléments $\mathrm{A}, 10 \mathrm{ml}$; eau distillée, $500 \mathrm{ml}$; tampon phosphate $\mathrm{pH} 6,50,2 \mathrm{M}, 500 \mathrm{ml}$; $\mathrm{pH}$ final du milieu 6,5.

La solution A d'oligo-éléments est ainsi composée (Meyers et Knight, 1958) : $\mathrm{CuCl}_{2} 15,5 \mathrm{mg} ; \mathrm{ZnSO}_{4}, 7 \mathrm{H}_{2} \mathrm{O}, 175,6 \mathrm{mg} ; \mathrm{MnCl}_{2}, 4 \mathrm{H}_{2} \mathrm{O}$, $36 \mathrm{mg}$; $\mathrm{CaCl}_{2}, 2 \mathrm{H}_{2} \mathrm{O}, 183,4 \mathrm{mg}$; $\left(\mathrm{NH}_{4}\right)_{\leftarrow} \mathrm{Mo}_{\tau} \mathrm{O}_{24}, 4 \mathrm{H}_{2} \mathrm{O}, 10,2 \mathrm{mg}$; eau distillée $100 \mathrm{ml}$.

Le milieu est réparti soit en erlenmeyer de $150 \mathrm{ml}$ à raison de $40 \mathrm{ml}$ par fiole, soit en erlenmeyer de $250 \mathrm{ml}$ à raison de $60 \mathrm{ml}$ par fiole. Les erlenmeyers sont bouchés au coton cardé et stérilisés par autoclavage à $115^{\circ} \mathrm{C}$ pendant $20 \mathrm{mn}$. 


\subsection{Conditions de culture}

Après inoculation les fioles, au nombre de 3 par essai, sont placées à l'étuve à $20^{\circ} \mathrm{C}$ pendant au moins $12 \mathrm{j}$ sans agitation ou, dans le cas d'essais en milieu agité, disposées sur un agitateur New Brunswick animé d'un mouvement alternatif de 120 secousses par mn, secousses d'une amplitude de $5 \mathrm{~cm}$; l'incubation se fait alors à 23 ou $25^{\circ} \mathrm{C}$ pendant 6-8 j.

L'infiuence de la température sur la croissance et la production d'enzymes a été étudiée à l'aide d'un incubateur permettant l'obtention d'un gradient linéaire de température. Les cuves de l'incubateur contiennent $20 \mathrm{ml}$ de milieu maintenu en mouvement par agitation magnétique.

A la fin de la période d'incubation le milieu de culture est filtré, centrifugé puis ajusté à $\mathrm{pH} 6$ si nécessaire. Le liquide obtenu constitue la préparation enzymatique. Le mycélium séparé par filtration est lavé deux ou trois fois à l'eau, séché à $102^{\circ} \mathrm{C}$ pendant $15 \mathrm{~h}$ et pesé.

\subsection{Détermination de l'activité enzymatique}

L'activité protéasique des préparations est déterminée dans les conditions décrites antérieurement (Lenoir et Choisy, 1971). Le mélange réactionnel a la composition suivante : caséinate de sodium 2,5 p. $100,2.5 \mathrm{ml}$; tampon mixte acétate-borate-phosphate $0,25 \mathrm{M}$ $\mathrm{pH} 6,0,5 \mathrm{ml}$; préparation enzymatique, $1 \mathrm{ml}$; eau distillée, $1 \mathrm{ml}$.

La digestion est conduite à $40^{\circ} \mathrm{C}$ pendant $2 \mathrm{~h}$. Après précipitation des protéines par l'acide trichloracétique à 12 p. 100 ou à 2 p. 100 la quantité de composés azotés solubles est estimée par un dosage colorimétrique des groupements tyrosine et tryptophane à l'aide du réactif de Folin et Ciocalteu (1927), selon la méthode d'Anson (1938).

Certains essais ont été réalisés dans des conditions un peu différentes. La caséine est mise en solution à 2 p. 100 en tampon phosphate $0,05 \mathrm{M}$ pH 6,5 et le mélange réactionnel est constitué de 2,5 ml de solution de caséine et $2,5 \mathrm{ml}$ de préparation enzymatique. La digestion s'effectue en $3 \mathrm{~h}$ à $40^{\circ} \mathrm{C}$ et le mélange est déféqué par addition d'un volume égal d'acide trichloracétique à 5 p. 100. Sur le filtrat trichloracétique les composés azotés non protéiques sont estimés soit par mesure de la densité optique à $280 \mathrm{~nm}$ selon la méthode de Kunitz (1947), soit avec le réactif de Folin-Ciocalteu selon la méthode d'Anson (1938).

\subsection{Essais d'induction du système protéolytique}

Le mycélium utilisé pour les essais d'induction en l'absence de croissance est préparé de la façon suivante : le mycélium produit au cours d'une culture de $5 \mathrm{j}$ en milieu agité est recueilli aseptiquement 
par filtration puis lavé deux fois avec de l'eau distillée stérile. Le mycélium est ensuite agité pendant une nuit à $3-4^{\circ} \mathrm{C}$ dans du tampon phosphate $0,05 \mathrm{M}$ à $\mathrm{pH} 6,5$.

La détermination de l'activité protéolytique libérée par le mycélium est réalisée par mise en suspension de $500 \mathrm{mg}$ de ce dernier dans $20 \mathrm{ml}$ de la solution à essayer ; le mélange est alors agité pendant $6 \mathrm{~h}$ à $18^{\circ} \mathrm{C}$.

\section{II. - RESULTATS}

\subsection{Les caractères du système protéolytique de la souche P1 de P. caseicolum. Données préliminaires}

Les conditions de détermination de l'activité protéolytique ont été précisées au cours d'essais préliminaires qui ont notamment permis de fixer la composition du mélange réactionnel, le temps et la température d'incubation du mélange (Lenoir et Choisy, 1971).

Deux facteurs de l'activité sont particulièrement importants à considérer pour le choix des conditions les plus favorables à l'étude de la production du système protéolytique, le $\mathrm{pH}$ et la température au double plan de l'activité et de la stabilité des enzymes.

\subsubsection{INFLUENCE DU pH SUR L'ACTIVITÉ PROTÉOLYTIQUE DU SURNA- GEANT DE CULTURE}

Le mélange réactionnel est tamponné à divers $\mathrm{pH}$ dans l'intervalle 4 - 11 à l'aide d'un tampon mixte acétate-borate-phosphate et la réaction est réalisée à $40^{\circ} \mathrm{C}$ pendant $2 \mathrm{~h}$. Trois séries de déterminations ont été réalisées à partir de surnageants de culture de $12 \mathrm{j}$ à $20^{\circ} \mathrm{C}$ en milieu non agité. Bien que les résultats ne soient pas rigoureusement concordants dans la zone de pH 7-9 une courbe moyenne caractéristique peut être tracée (fig. 1) et son allure met en évidence un pH optimal compris dans l'intervalle 5,5 - 6,5 et un épaulement dans la zone de $\mathrm{pH} 7,5$ - 9,0 qui suggère un optimum secondaire à $\mathrm{pH}$ proche de 8,5 .

\subsubsection{INFLUENCE du pH SUR la stabilité du Système PROTÉolytique}

Le surnageant de culture, amené à différents $\mathrm{pH}$ dans l'intervalle 4 - 11 en présence d'un tampon mixte acétate-borate-phosphate 0,025 M est maintenu à $37^{\circ} \mathrm{C}$ pendant $1 \mathrm{~h}$; il est ensuite ajusté à $\mathrm{pH} 6,0$ et l'activité restante est déterminée comme il est indiqué précédemment.

Deux séries d'essais ont été réalisées, leurs résultats (fig. 2) montrent que la zone de stabilité maximale se situe entre $\mathrm{pH} 5$ et 6,5 avec un optimum à $\mathrm{pH} 6,0$. L'inactivation apparaît totale à $\mathrm{pH} 4,0$; en zone alcaline la stabilité du système est notablement plus grande, à pH 8,5 l'inactivation atteint seulement 50 p. 100 . 


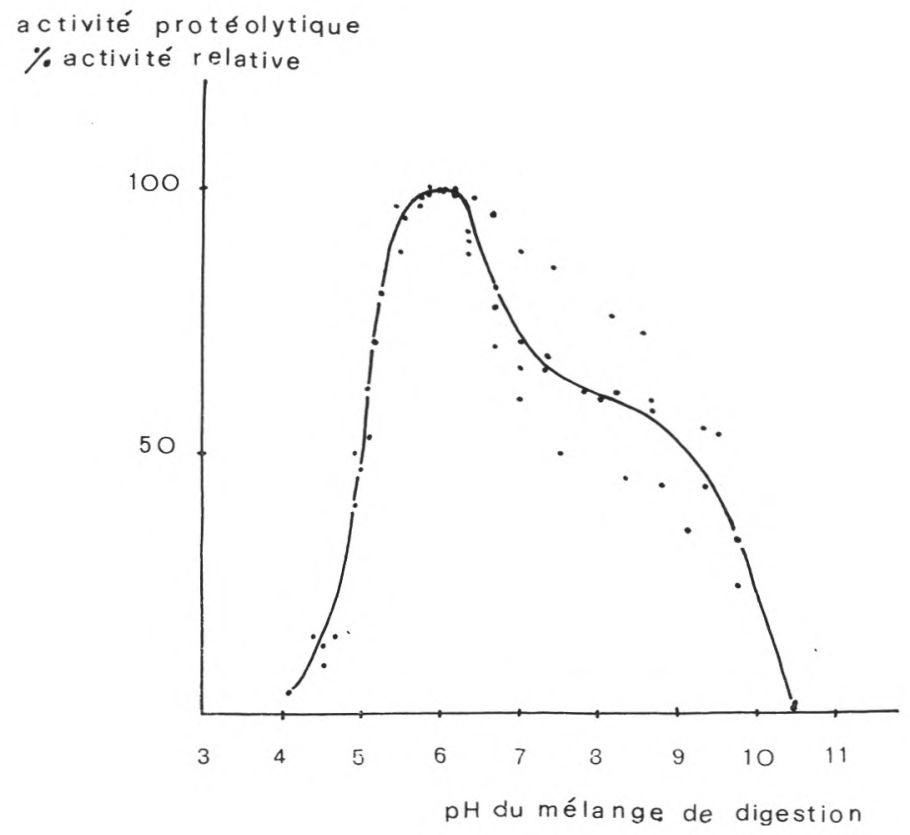

fig. 1

Influence du $\mathrm{pH}$ sur l'activité protéolytique de $P$. caseicolum (Souche $\mathrm{P}_{1}$, culture non agitée) (courbe moyenne établie à partir de trois séries de détermination).

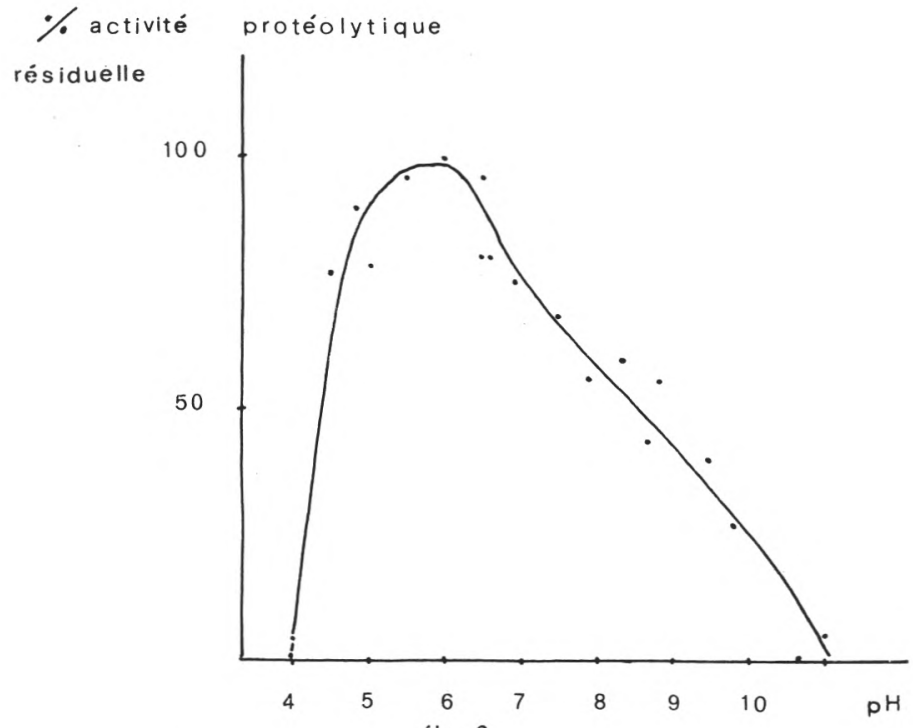

fig. 2

Stabilité de l'activité protéolytique de $P$. caseicolum en fonction du $\mathrm{pH}$ (Souche $\mathbf{P}_{1}$, culture non agitée). Temps de conservation $1 \mathrm{~h}-37^{\circ} \mathrm{C}$ en tampon mixte acétate-borate-phosphate $0,025 \mathrm{M}$.

(courbe moyenne établie à partir de deux séries de détermination). 
a ctivité protéolytique

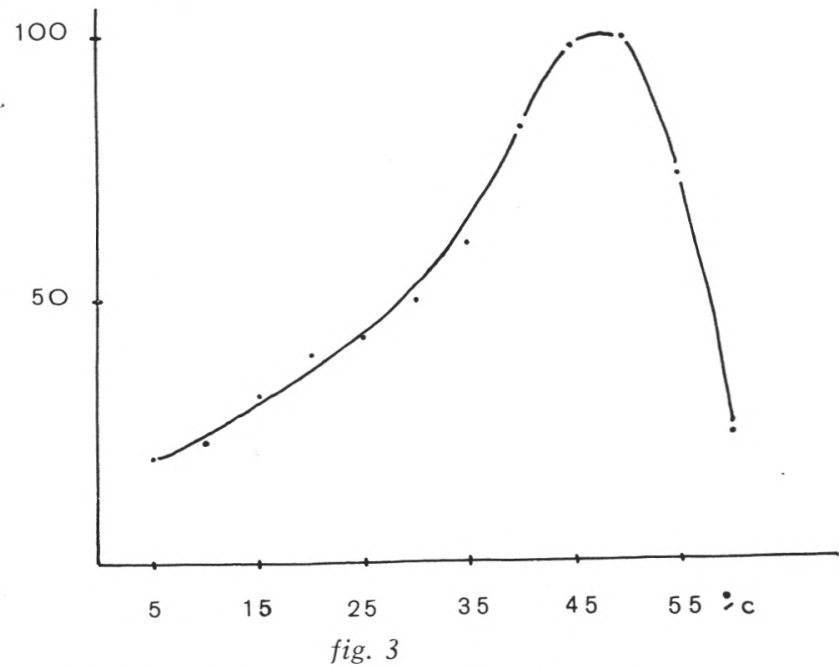

Influence de la température d'incubation sur l'activité protéolytique de $P$. caseicolum. (Souche $\mathrm{P}_{1}$, culture non agitée) $\mathrm{pH}$ du mélange réactionnel : 6,0 .

\% activité protéolytique restante

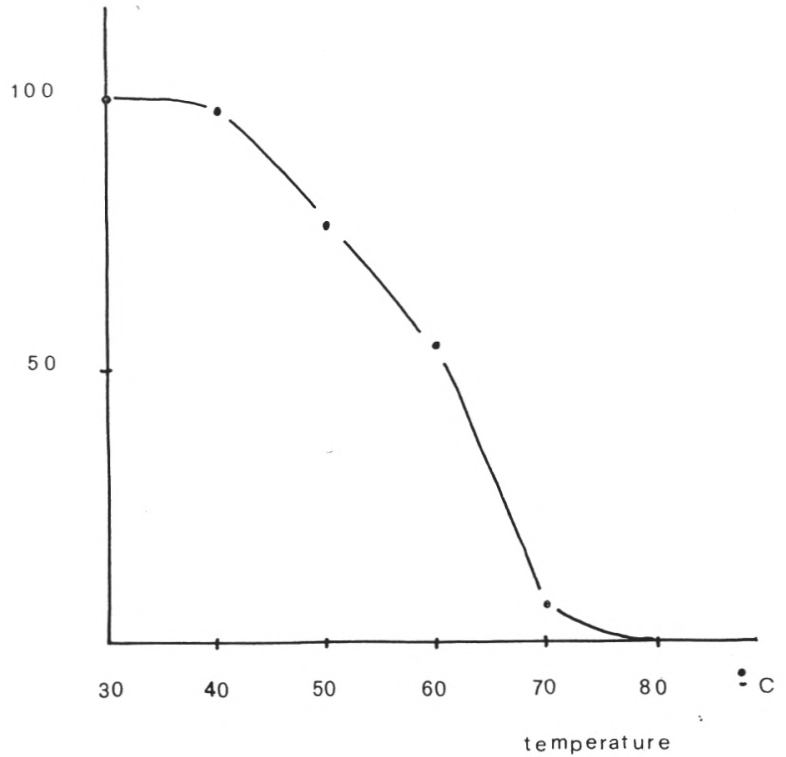

fig. 4

Stabilité thermique du système protéolytique de $P$. caseicolum (Souche $\mathbf{P}_{1}$, culture non agitée).

Activité restante après $10 \mathrm{mn}$ de chauffage à pH 6,5. 


\subsubsection{INFLUENCE DE LA TEMPÉRATURE SUR L'ACTIVITÉ ENZYMATIQUE}

L'influence de la température d'incubation a été estimée dans l'intervalle $5-60^{\circ} \mathrm{C}$, pour des temps de $2 \mathrm{~h}$ de 25 à $60^{\circ} \mathrm{C}$ et de $24 \mathrm{~h}$ de 5 à $30^{\circ} \mathrm{C}, 1 \mathrm{e} \mathrm{pH}$ du mélange réactionnel étant 6,0 .

La courbe de la figure 3 met en évidence une température optimale de $45-50^{\circ} \mathrm{C}$ et une diminution très nette d'activité aux températures supérieures à $50^{\circ} \mathrm{C}$, l'inactivation thermique se faisant sentir dès que la température dépasse $40^{\circ} \mathrm{C}$.

\subsubsection{Stabilité thermique du système protéolytique}

Le surnageant de culture amené à $\mathrm{pH}$ 6,5 est chauffé à différentes températures pendant $10 \mathrm{mn}$ et l'activité protéolytique résiduelle est déterminée. L'allure de la courbe obtenue (fig. 4) confirme l'observation précédente. La stabilité du système enzymatique n'est pratiquement pas altérée à $40^{\circ} \mathrm{C}$; aux températures supérieures elle baisse rapidement, à $60^{\circ} \mathrm{C}$ il reste seulement 50 p. 100 de l'activité initiale et à $80^{\circ} \mathrm{C}$ l'inactivation est totale.

Les caractères ainsi mis en évidence montrent qu'il s'agit d'un système protéolytique actif à $\mathrm{pH}$ neutre et, par suite, différent de la protéase acide, de $\mathrm{pH}$ optimum 3,0, dont la production a été signalée par Tsugo et Matsuoka (1963).

\subsection{Les niveaux de production du système protéolytique}

L'aptitude de $P$. caseicolum à la production d'enzymes protéolytiques a été déterminée antérieurement sur une centaine de souches de diverses origines (Lenoir et Choisy, 1971). Les niveaux de production, exprimés en tyrosine libérée par $\mathrm{ml}$ de milieu et par heure de

TABLEAU 1

Niveau de production du système protéolytique à diverses étapes de l'étude*

\begin{tabular}{c|c|c|c}
\hline & \multicolumn{3}{|c}{ Niveaux de production en } \\
\cline { 2 - 3 } Souches & mars 1968 & septembre 1969 & juillet 1970 \\
\cline { 2 - 3 } P 1 & 500 & 1300 & 2300 \\
PL 21 & 600 & 1400 & 2600 \\
PN 14 & 530 & - & 1900 \\
PC 12 & 690 & - & 3800 \\
\hline
\end{tabular}

* Niveaux de production exprimés en $\mu \mathrm{g}$ de tyrosine libérée par $\mathrm{ml}$ de milieu et par heure de digestion, tyrosine soluble en T.C.A. 2 p. 100.

Conditions de cultures : milieu Czapek-trypticase, incubation $12 \mathrm{j}$ à $20^{\circ} \mathrm{C}$, sans agitation. 
digestion (tyrosine soluble en TCA 12 p. 100) se situaient alors entre 200 et $500 \mu \mathrm{g}$. Par la suite, les activités protéolytiques ont été déterminées à plusieurs reprises au cours des repiquages successifs. Pour les quatre souches examinées il a été observé entre mars 1968 et juillet 1970, un accroissement très net des niveaux de production d'enzymes ceux-ci étant multipliés par un facteur proche de 4-5 (tab. 1), alors que les croissances mycéliennes n'étaient pas modifiées. Ensuite les niveaux de production observés sont restés pratiquement stables.

Cet accroissement du potentiel de production d'enzymes peut être attribué à une adaptation des souches au milieu de culture ou à des mutations. On remarquera cependant que l'augmentation relevée est très supérieure à celles qui ont été jusqu'ici observées chez les moisissures pour des mutations provoquées (Sekin et al., 1969).

Il est également intéressant de rapprocher la production d'enzymes et la croissance du mycélium. La figure 5 reproduit un certain nombre de courbes mettant en évidence les cinétiques du développement mycélien et de la production enzymatique en milieu liquide non agité.

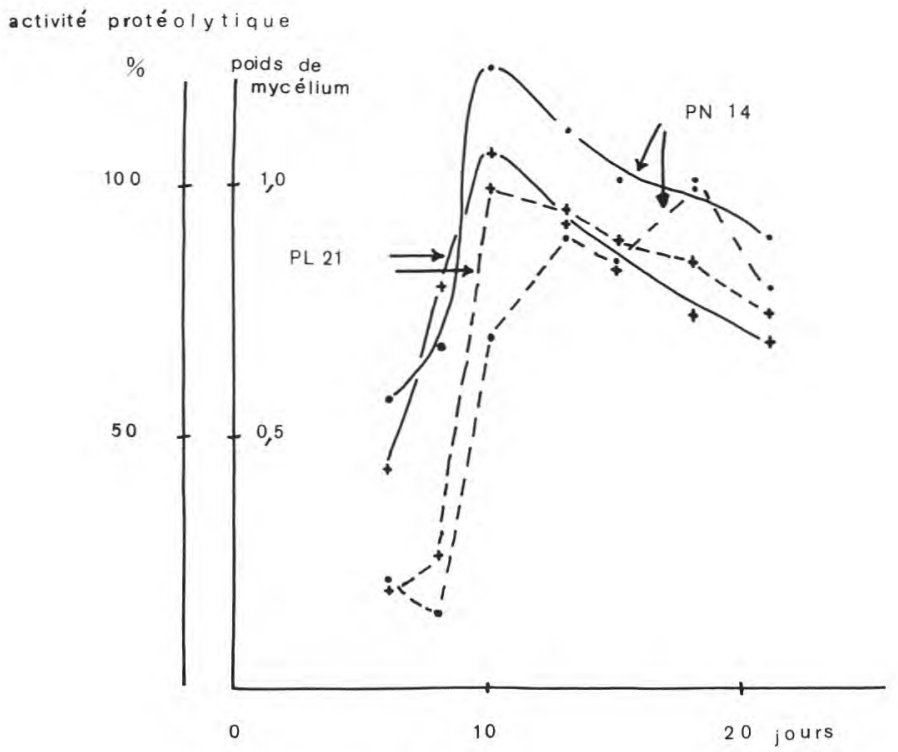

fig. 5

Croissance et production d'enzymes protéolytiques chez $P$. caseicolum.

(Souches Pl 21 et PN 14, cultures non agitées).

\section{Activité protéolytique en pourcentages relatifs.}

Poids de mycélium en g par litre. 


\subsection{Les facteurs de production du système protéolytique liés à la composition du milieu de culture chez la souche P1}

La composition du milieu joue un grand rôle dans la production d'enzymes par les moisissures et il est fréquent qu'avec les milieux permettant une bonne croissance du mycélium on n'obtienne pas la quantité maximale d'enzymes. Selon Banks et al. (1967) un milieu destiné à la production d'enzymes doit présenter les caractères suivants :

- contenir les éléments nutritifs nécessaires à la croissance du micro-organisme,

— posséder un bon équilibre des divers éléments nutritifs,

- avoir un $\mathrm{pH}$ convenable,

- contenir un précurseur, par exemple des acides aminés qui ne peuvent être synthétisés par la cellule,

- contenir un inducteur de l'activité enzymatique.

Pour l'étude des facteurs de production des enzymes protéolytiques chez $P$. caseicolum nous avons choisi comme milieu de base le milieu Czapek-Dox et, tenant compte des résultats obtenus lors d'essais préliminaires, nous avons substitué à la source d'azote minérale une source d'azote protidique, la trypticase (une peptone trypsique de caséine) et enrichi le milieu en oligo-éléments.

Le milieu retenu, Czapek-trypticase A, a une composition telle que par élimination ou substitution d'un composé il est possible de déterminer son influence sur le métabolisme du champignon, notamment sur la production d'enzymes.

\subsubsection{INFLUENCE DE LA SOURCE D'AZOTE}

Pour cette étude, le milieu Czapek-trypticase A a été modifié par remplacement de la source d'azote ou variation des teneurs en matières azotées. Ont été essayés les différents composés azotés suivants :

- trypticase aux doses de $5-10$ - 20 et 50 g par litre, soit environ $0,75-1,5-3$ et $7,5 \mathrm{~g}$ d'azote par litre.

- peptones d'origines diverses à la dose de $10 \mathrm{~g}$ par litre,

- caséine aux doses de 10 et $20 \mathrm{~g}$ par litre soit 1,5 et $3 \mathrm{~g}$ d'azote par litre,

- mélange des 18 acides aminés naturels formes L, en proportions égales, ou mélange d'acides aminés constitué par un hydrolysat de caséine (Casaminoacids Difco) à la dose totale de $10 \mathrm{~g}$ par litre, soit environ $1,5 \mathrm{~g}$ d'azote par litre, par litre,

- nitrate de sodium à la dose de $3 \mathrm{~g}$ par litre, soit $0,5 \mathrm{~g}$ d'azote

- diverses sources d'azote non protidique, minérales ou organiques, sulfate et citrate d'ammonium, urée, aux taux correspondants à $1,5 \mathrm{~g}$ d'azote par litre. 
TABLEAU 2. - Influence de la source d'azote sur la production du système protéolytique chez P. caseicolum

\begin{tabular}{|c|c|c|c|c|c|}
\hline \multicolumn{2}{|c|}{ Source d'azote } & \multicolumn{2}{|c|}{ Culture non agitée } & \multicolumn{2}{|c|}{ Culture agitée } \\
\hline Nature & Concentration $\mathrm{g} / \mathrm{l}$ & $\mathrm{pH}$ final & Activité & $\mathrm{pH}$ final & Activité \\
\hline $\begin{array}{l}\text { Trypticase (Mérieux) } \\
\text { Casitone (Difco) } \\
\text { Tryptone (Difco) } \\
\text { Tryptose (Difco) } \\
\text { Protéose-peptone (Difco) } \\
\text { Polypeptone (Mérieux) } \\
\text { Soytone (Difco) } \\
\text { Casaminoacids (Difco) } \\
\text { Caséine (N.B.C.) } \\
\text { Nitrate de sodium } \\
\text { Sulfate d'ammonium }\end{array}$ & $\begin{array}{l}10 \\
10 \\
10 \\
10 \\
10 \\
10 \\
10 \\
10 \\
10 \\
3 \\
7,1\end{array}$ & $\begin{array}{l}6,5 \\
6,3 \\
6,5 \\
6,3 \\
6,4 \\
6,5 \\
6,2 \\
6,7 \\
6,4 \\
6,4 \\
-\end{array}$ & $\begin{array}{r}100 \\
160 \\
135 \\
135 \\
105 \\
100 \\
60 \\
60 \\
80 \\
15 \\
-\end{array}$ & $\begin{array}{l}6,7 \\
- \\
- \\
\overline{-} \\
6,7 \\
6,7 \\
\overline{6,2} \\
5,9 \\
4,5\end{array}$ & $\begin{array}{r}100 \\
- \\
- \\
- \\
100 \\
95 \\
40 \\
50 \\
15 \\
70\end{array}$ \\
\hline $\begin{array}{c}\text { Trypticase } \\
= \\
- \\
-\end{array}$ & $\begin{array}{r}5 \\
10 \\
20 \\
50\end{array}$ & $\begin{array}{l}6,6 \\
7,0 \\
8,0 \\
8,4\end{array}$ & $\begin{array}{r}95 \\
100 \\
75 \\
35\end{array}$ & $\begin{array}{l}- \\
-\end{array}$ & $\begin{array}{l}- \\
-\end{array}$ \\
\hline
\end{tabular}

Conditions des essais : Souche $\mathbf{P}_{1}$, incubation $20^{\circ} \mathrm{C}, 12 \mathrm{j}$ en culture non agitée, $25^{\circ} \mathrm{C}, 6 \mathrm{j}$ en culture agitée. Activité protéolytique exprimée en pourcentages relatifs. 
L'influence de la nature de la source d'azote est illustrée par les données figurant sur le tableau 2.

Les sources d'azote non protidique, minérales ou organiques, essayées se révèlent plus ou moins favorables à la production d'enzymes.

La présence de nitrate de sodium se traduit par une croissance et une production d'enzymes très nettement inférieures à celles observées avec les sources d'azote organique. Le sulfate d'ammonium permet un taux de production appréciable $(70$ p. 100 du taux témoin sur trypticase) ; en revanche, le citrate d'ammonium et l'urée inhibent toute production d'enzymes bien qu'ils permettent une croissance normale.

Il apparaît ainsi que $P$. caseicolum réagit favorablement à un apport de peptides au milieu de culture. Les différents hydrolysats protéiques essayés ne donnent cependant pas des résultats équivalents : casitone, tryptone et tryptose (Difco) semblent stimuler la production d'enzymes alors que soytone et casaminoacids sont moins favorables.

Le remplacement de la trypticase par une caséine Hammersten ne se traduit pas, en culture non agitée, par une différence importante de production. On note cependant que si la quantité d'enzymes produite est assez peu différente, la présence de trypticase favorise une production précoce. En milieu agité la différence apparaît plus nettement, probablement en raison de l'adoption de temps de culture plus courts.

La comparaison des résultats obtenus avec la trypticase et le mélange en proportions égales des acides aminés naturels ne fait pas apparaître de différence notable dans la production d'enzymes bien que les compositions en acides aminés de ces deux sources d'azote soient sensiblement différentes.

L'influence de concentrations croissantes d'azote protidique dans le milieu de culture a été éprouvée avec trypticase et caséine.

L'augmentation de la concentration en trypticase ou en caséine se traduit par une stimulation de la croissance, mais non de la production d'enzymes.

Ainsi on observe (tab. 2) que les taux de trypticase de 5 et $10 \mathrm{~g}$ par litre assurent des productions d'enzymes peu différentes et les proportions plus élevées, 20 et $50 \mathrm{~g}$ par litre, sont à l'origine d'une production enzymatique moindre. Il est probable que la diminution de production d'enzymes notée avec les fortes concentrations en trypticase soit liée à l'augmentation du $\mathrm{pH}$ final des cultures, $\mathrm{pH}$ qui atteint ou même dépasse 8 avec $20 \mathrm{~g}$ et $50 \mathrm{~g}$ de trypticase.

\subsubsection{INFLUENCE DE LA SOURCE DE CARBONE}

Le milieu Czapek-trypticase a été modifié par substitution de la source de carbone ou variation de la teneur en glucides. 
TABLEAU 3. - Influence de la source de carbone sur la production du système protéolytique chez P. caseicolum

\begin{tabular}{|c|c|c|c|c|c|}
\hline \multicolumn{2}{|c|}{ Source de carbone } & \multicolumn{2}{|c|}{ Culture non agitée } & \multicolumn{2}{|c|}{ Culture agitée } \\
\hline Nature & Concentration $\mathrm{g} / \mathrm{l}$ & $\mathrm{pH}$ final & Activité & $\mathrm{pH}$ final & Activité \\
\hline $\begin{array}{l}\text { Glucose } \\
\text { Lactose } \\
\text { Saccharose } \\
\text { Mannitol } \\
\text { Xylose } \\
\text { Glycérol }\end{array}$ & $\begin{array}{l}20 \\
20 \\
20 \\
20 \\
20 \\
10\end{array}$ & $\begin{array}{l}6,4 \\
6,7 \\
7,1 \\
6,7 \\
6,3 \\
7,0\end{array}$ & $\begin{array}{r}100 \\
25 \\
45 \\
35 \\
45 \\
30\end{array}$ & $\begin{array}{l}6,2 \\
6,6 \\
- \\
- \\
-\end{array}$ & $\begin{array}{r}100 \\
95 \\
- \\
- \\
-\end{array}$ \\
\hline $\begin{array}{c}\text { Glucose } \\
- \\
- \\
-\end{array}$ & $\begin{array}{r}5 \\
10 \\
50 \\
100\end{array}$ & $\begin{array}{l}6,9 \\
6,7 \\
5,7 \\
4,5\end{array}$ & $\begin{array}{l}45 \\
65 \\
80 \\
65\end{array}$ & $\begin{array}{l}6,8 \\
6,7 \\
6,0 \\
\underline{-}\end{array}$ & $\begin{array}{r}55 \\
125 \\
85 \\
-\end{array}$ \\
\hline $\begin{array}{l}\text { Saccharose } \\
-\end{array}$ & $\begin{array}{l}10 \\
40\end{array}$ & $\begin{array}{l}7,2 \\
6,5\end{array}$ & $\begin{array}{l}40 \\
40\end{array}$ & $\frac{6,7}{-}$ & $\underline{70}$ \\
\hline
\end{tabular}

Conditions des essais : souche $P_{1}$, incubation $20^{\circ} \mathrm{C}, 12 \mathrm{j}$ en culture non agitée, $25^{\circ} \mathrm{C}, 6 \mathrm{j}$ en culture agitée.

Activité protéolytique exprimée en pourcentages relatifs. 
Les substrats carbonés suivants ont été essayés :
- glucose aux taux de
5 - 10 - 20 - 40 - 50 - 100 g par litre,
- glycérol aux taux de
- saccharose aux taux de
- lactose au taux de
- xylose au taux de
- mannitol au taux de
- maltose au taux de
5 - 10 - $20-50$ g par litre,
10 - 20 - 40 g par litre,
$20 \mathrm{~g}$ par litre,
$20 \mathrm{~g}$ par litre,
20 g par litre,
$10 \mathrm{~g}$ par litre,
- acide glutamique en quantité telle qu'elle apporte un taux de carbone équivalent à $10 \mathrm{~g}$ de glucose,
- amidon au taux de $10 \mathrm{~g}$ par litre,

L'influence de la nature de la source de carbone est concrétisée par les données figurant sur le tableau 3. Tous les essais réalisés en culture non agitée montrent que la source de carbone permettant d'obtenir la production d'enzymes maximale est le glucose. Cette production est près de deux à trois fois plus grande que celle observée avec les autres sources de carbone bien que les développements mycéliens soient sensiblement les mêmes. Avec les sucres autres que le glucose on décèle quelques différences importantes dans les synthèses enzymatiques, par exemple entre le lactose et le saccharose.

L'influence de la concentration en sucre est également appréciable (tab. 3).

Il est clair en effet qu'il existe une teneur en sucre optimale pour la production d'enzymes. Avec le glucose comme source de carbone cette teneur se situe aux environs de 20 à $40 \mathrm{~g}$ par litre, cette dernière ne permettant pas d'obtenir une production sensiblement plus élevée que la précédente. Aux doses nettement supérieures, par exemple $100 \mathrm{~g}$, il n'y a pas augmentation mais diminution de la quantité d'enzymes, malgré l'accroissement sensible du poids de mycélium. Cette diminution pourrait être due à l'acidification du milieu, le $\mathrm{pH}$ pouvant descendre au-dessous de 5,5.

\subsubsection{InFluence D'UNE MOdification SimultanéE DES SOURCES DE CARBONE ET D'AZOTE}

Les essais ont comporté une modification du rapport $\mathrm{C} / \mathrm{N}$, pour un couple $\mathrm{C}-\mathrm{N}$ donné, et une modification du couple $\mathrm{C}-\mathrm{N}$, pour un rapport $\mathrm{C} / \mathrm{N}$ constant.

L'influence des variations du rapport $C / N$ a été plus particulièrement étudiée avec le couple glucose-trypticase. Les résultats les plus caractéristiques sont groupés sur le tableau 4.

On observera que le rapport $\mathrm{C} / \mathrm{N}$ dans l'intervalle des valeurs 0,5 - 5 influe relativement peu sur la production d'enzymes. Le rapport le plus favorable paraît être voisin de 2, la combinaison la plus satisfaisante étant $20 \mathrm{~g}$ de glucose et $10 \mathrm{~g}$ de trypticase. Une teneur plus élevée en trypticase et moindre en glucose se traduit par un $\mathrm{pH}$ trop élevé (voisin de 8,0 ), un taux de glucose plus fort et de trypticase 
TABLEAU 4

Influence des concentrations respectives des sources de carbone et d'azote sur la production du système protéolytique chez P. caseicolum

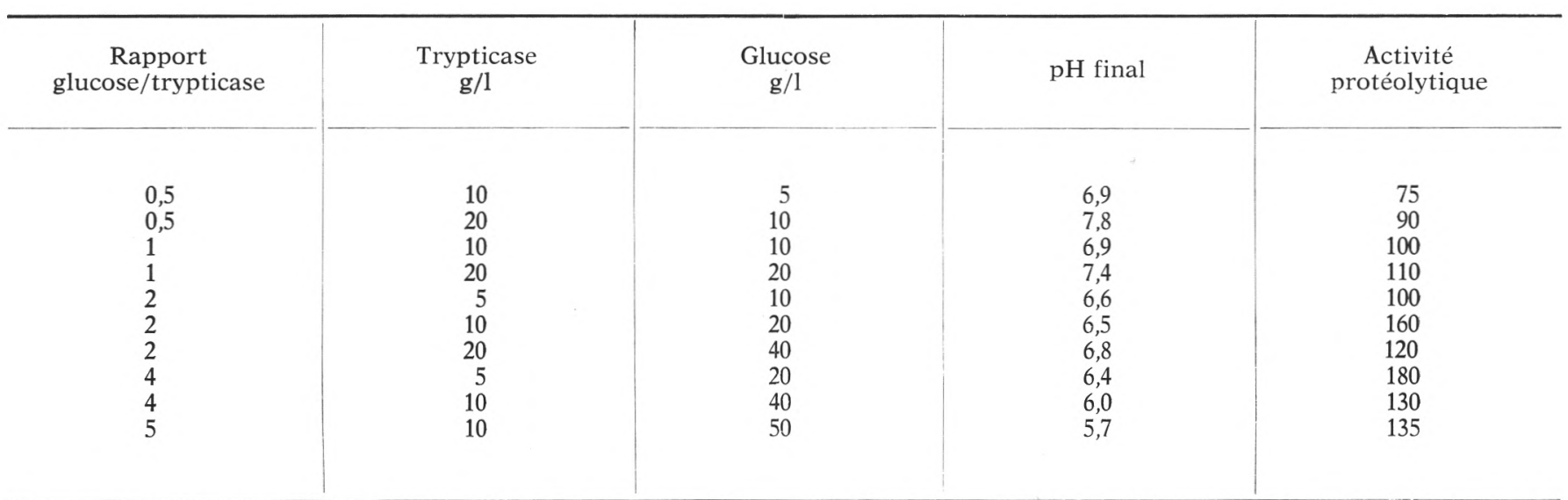

Conditions des essais : Souche $\mathrm{P}_{1}$, incubation $12 \mathrm{j}$ à $20^{\circ} \mathrm{C}$, culture non agitée.

Activité protéolytique exprimée en pourcentages relatifs. 
plus faible tend au contraire à donner une acidification trop poussée du milieu ( $\mathrm{pH}$ inférieur à 6). Dans les deux cas la production d'enzymes risque d'être abaissée.

Les essais concernant les variations du rapport $\mathrm{C} / \mathrm{N}$ avec le saccharose comme source de carbone et la trypticase comme source d'azote montrent que ce facteur a peu d'influence dans les limites de 0,5 à 4 , pour des teneurs en trypticase de 10 et $20 \mathrm{~g}$ par litre.

L'influence d'une modification $d u$ couple $C-N$ a été seulement éprouvée avec les combinaisons glucose-trypticase, glucose-caséine, saccharose-trypticase et saccharose-caséine.

Il est observé que le couple glucose-trypticase permet d'atteindre le niveau de production le plus élevé ; cependant avec le saccharose comme source de carbone, la caséine représente la source d'azote la plus favorable à la production des enzymes protéolytiques.

\subsubsection{INFLUENCE DE « L'ALIMENTATION » MINÉRALE}

On sait que de nombreux éléments minéraux tels le fer, le zinc, le manganèse, le potassium, le magnésium, sont indispensables au développement des champignons et certains sont parfois nécessaires pour la production d'enzymes protéolytiques (Davies, 1963).

Les essais réalisés avec $P$. caseicolum ont porté sur l'influence de la concentration en calcium, en magnésium, en oligo-éléments et en diverses formes de soufre. L'influence de la concentration en phosphates a été également éprouvée.

Le calcium exerce une influence sur l'activité et la stabilité d'un grand nombre d'enzymes exocellulaires. Chez $P$. caseicolum, en revanche, l'addition de chlorure de calcium à des concentrations $0,01 \mathrm{M}$ ou $0,005 \mathrm{M}$ se traduit par une diminution sensible de la production d'enzymes; ainsi, à la concentration $0,01 \mathrm{M}$, la diminution atteint 50 p. 100 . Le milieu témoin utilisé dans cet essai contient seulement $1 \mathrm{~g}$ de phosphate dipotassique et $1 \mathrm{ml}$ de solution d'oligo-éléments, sa concentration en $\mathrm{CaCl}_{2}$ est proche de $10^{-5} \mathrm{M}$.

Le magnésium est indispensable à la production du système protéolytique chez $P$. caseicolum. L'absence de sulfate de magnésium dans le milieu se traduit en effet par une forte diminution de l'activité protéolytique du surnageant de culture celle-ci représentant seulement 10 p. 100 de l'activité du témoin (tab. 5). En portant la dose en magnésium du milieu de $0,5 \mathrm{~g} / 1$, dose utilisée normalement, à $1 \mathrm{~g} / 1$, l'activité protéolytique est augmentée d'environ $20 \mathrm{p} .100$. L'action du magnésium sur la croissance est également notable mais elle est beaucoup moins marquée, l'absence de magnésium n'entraînant qu'une diminution de poids de 20 p. 100 par rapport au témoin.

L'effet de la concentration en sulfates a été éprouvé dans l'intervalle de concentrations en $\mathrm{Na}_{2} \mathrm{SO}_{*}$ de $10^{-2}$ à $10^{-4} \mathrm{M}$, le milieu témoin utilisé étant le Czapek-trypticase A dans lequel sulfate de magnésium et sulfate de fer ont été remplacés par des quantités équivalentes de 
TABLEAU 5. - Influence de certains sels minéraux sur la production du système protéolytique chez $P$. caseicolum

\begin{tabular}{|c|c|c|c|}
\hline \multicolumn{2}{|c|}{ Sels minéraux ajoutés } & $\mathrm{pH}$ final & $\begin{array}{c}\text { Activité } \\
\text { protéolytique }\end{array}$ \\
\hline Czapek-trypticase normal & $(\mathrm{CT})$ & 6,4 & 100 \\
\hline Phosphate & $0,006 \mathrm{M}$ & 7,6 & 35 \\
\hline- & $0,025 \mathrm{M}$ & 6,7 & 95 \\
\hline - & $0,05 \mathrm{M}$ & 6,5 & 90 \\
\hline- & $0,25 \mathrm{M}$ & 6,1 & 115 \\
\hline Sulfates $\left(\mathrm{Na}^{2} \mathrm{SO}^{4}\right)$ & 0 & 6,8 & 50 \\
\hline$-\quad\left(\mathrm{Na}^{2} \mathrm{SO}^{4}\right)$ & $0,01 \mathrm{M}$ & 6,8 & 50 \\
\hline Sulfates $\mathrm{Mg}$ et $\mathrm{Fe}$ & 0 & 6,5 & 10 \\
\hline Sulfates $\mathrm{Mg}$ et $\mathrm{Fe}$ & double concentration & 6,6 & 120 \\
\hline Sulfate $\mathrm{Mg}$ & 0 & - & 10 \\
\hline Sulfate $\mathrm{Fe}$ & 0 & - & 100 \\
\hline Remplacement $\mathrm{MgSO}^{4}$ et & équivalents en $\mathrm{MgCl}^{2}$ et $\mathrm{FeCl}^{2}$ & - & 90 \\
\hline Hyposulfite de sodium & $0,004 \mathrm{M}$ & 6,7 & 150 \\
\hline Sulfite de sodium & $0,004 \mathrm{M}$ & 6,7 & 150 \\
\hline Oligo-éléments & 0 & 6,5 & 30 \\
\hline - solution A & $1 \mathrm{ml}$ & 6,5 & 65 \\
\hline - solution $\mathrm{B}$ & $10 \mathrm{ml}$ & 6,4 & 35 \\
\hline - solutions $\mathrm{A}$ et $\mathrm{B}$ & $10 \mathrm{ml}$ & 6,4 & 120 \\
\hline
\end{tabular}

Conditions des essais : Souche $\mathrm{P}_{1}$, incubation $12 \mathrm{j}$ à $20^{\circ} \mathrm{C}$, culture non agitée.

Composition de la solution d'oligo-éléments $\mathrm{B}$ : $\mathrm{Pb}\left(\mathrm{NO}_{3}\right)_{2} 80 \mathrm{mg}$; $\mathrm{CoSO}_{4}, 7 \mathrm{H}_{2} \mathrm{O} 202 \mathrm{mg}$; NiCl${ }^{2}, 6 \mathrm{H}_{2} \mathrm{O} 200 \mathrm{mg} ; \mathrm{BaCl}^{2}, 2 \mathrm{H}_{2} \mathrm{O}$ $85 \mathrm{mg} ; \mathrm{Na}^{2} \mathrm{~B}^{4} \mathrm{O}^{7}, 7 \mathrm{H}_{2} \mathrm{O}, 440 \mathrm{mg}$.

Activité protéolytique exprimée en pourcentages relatifs. 
chlorures. L'addition de sulfate ne semble avoir aucun effet sur la production d'enzymes, ni effet dépressif, ni effet favorable (tab. 5). On notera toutefois que le milieu témoin contenait, du fait de la présence de la solution d'oligo-éléments, une dose de sulfate de zinc proche de $0,5 \cdot 10^{-4} \mathrm{M}$.

D'autres formes de soufre ont été ajoutées au milieu, notamment sulfite, hyposulfite et cystéine. L'apport de sulfite et d'hyposulfite à la dose de $1 \mathrm{~g} / 1$ se traduit par un accroissement sensible de la production d'enzymes (tab. 5) ; en revanche la présence de cystéine tend à réduire cette production.

La présence d'oligo-éléments minéraux est un facteur important de la synthèse des enzymes chez $P$. caseicolum. On notera en effet (tab. 5) qu'en milieu privé d'oligo-éléments la production d'enzymes est nettement abaissée, une proportion convenable de la solution A utilisée $(10 \mathrm{ml})$ étant nécessaire pour assurer une production optimale. En outre, un apport d'oligo-éléments supplémentaires (solution B avec $\mathrm{Pb}, \mathrm{B}, \mathrm{Co}, \mathrm{Ni}, \mathrm{Ba}$ ), à des doses de $1 \mathrm{mg}$ par litre de milieu, permet d'accroître de 20 p. 100 l'activité protéolytique du surnageant de culture.

La présence de phosphates est nécessaire à la croissance et à la synthèse des enzymes et le milieu Czapek-trypticase originel contenait comme le milieu de Czapek-Dox, 1 g par litre de phosphate dipotassique soit une concentration proche de $0,6-10^{-2} \mathrm{M}$. Cette quantité est certainement suffisante pour assurer le développement convenable du champignon. L'apport d'une quantité supplémentaire de phosphate a été essayée tant pour maintenir le $\mathrm{pH}$ à une valeur proche du $\mathrm{pH}$ initial que pour accroître la force ionique du milieu. On remarque (tab. 5) que l'emploi d'un tampon phosphate, à une concentration suffisante, de l'ordre de 0,05 à $0,1 \mathrm{M}$, permet de limiter assez sensiblement l'évolution du $\mathrm{pH}$ du milieu de culture au cours de l'incubation et ce facteur se traduit par une augmentation notable de la production d'enzymes.

\subsubsection{ESSAIS DE MILIEUX DIVERS}

La recherche de conditions de milieu permettant une production optimale d'enzymes protéolytiques a conduit à essayer d'une part diverses supplémentations du milieu de base, d'autre part des milieux de culture différents, milieux naturels plus ou moins enrichis.

L'influence d'une addition de facteurs de croissance a été éprouvée par incorporation au milieu de base d'extrait et d'autolysat de levure, d'extrait de malt, de son de blé et de son d'orge (tab. 6).

L'addition d'extrait de levure (Difco) ou d'autolysat de levure (Difco) à la dose de $5 \mathrm{~g}$ par litre n'entraîne aucune augmentation de la croissance du mycélium et de la production d'enzymes. Le seul effet apparent est une élévation du $\mathrm{pH}$ final des cultures de 0,3 à 0,4 unité $\mathrm{pH}$. 
TABLEAU 6. - Croissance et production du système protéolytique chez $P$. caseicolum sur divers milieux de culture

\begin{tabular}{|c|c|c|c|}
\hline Milieux & $\begin{array}{c}\text { Poids de } \\
\text { mycélium g/1 }\end{array}$ & pH final & $\begin{array}{c}\text { Activité } \\
\text { protéolytique }\end{array}$ \\
\hline $\begin{array}{lr}\text { Czapek-trypticase A (CT) } & \\
\text { CT + extrait de levure } & (5 \mathrm{~g} / 1) \\
\mathrm{CT}+\text { autolysat de levure } & (5 \mathrm{~g} / 1) \\
\mathrm{CT}+\text { extrait de malt } & (5 \mathrm{~g} / 1) \\
\mathrm{CT}+\text { infusion de son (de blé ou orge) } & \\
\text { Extrait de malt } & (30 \mathrm{~g} / 1) \\
\text { Extrait de malt }+ \text { trypticase }(5 \mathrm{~g} / \mathrm{l})+\text { oligo-éléments } \\
\text { Lactosérum } \\
\text { Lactosérum supplémenté } \\
\text { Lactosérum dilué au } 1 / 2 \text { avec tampon phosphate } 0,2 \mathrm{M} \\
\text { Lait papaïné } \\
\text { Lait papaïné supplémenté }\end{array}$ & $\begin{array}{l}11,0 \\
11,5 \\
- \\
\overline{-} \\
3,7 \\
11,2 \\
10 \\
13,5 \\
\frac{-}{22} \\
22\end{array}$ & $\begin{array}{l}6,4 \\
6,7 \\
6,8 \\
6,3 \\
6,7 \\
6,0 \\
6,1 \\
5,5 \\
5,2 \\
6,3 \\
6,4 \\
6,4\end{array}$ & $\begin{array}{r}100 \\
95 \\
95 \\
100 \\
85 \\
8 \\
85 \\
2 \\
2 \\
2 \\
50 \\
55\end{array}$ \\
\hline
\end{tabular}

Conditions des essais : Souche $\mathrm{P}_{1}$, incubation $12 \mathrm{j}$ à $20^{\circ} \mathrm{C}$, culture non agitée.

Activité protéolytique exprimée en pourcentages relatifs. 
Une supplémentation du milieu en extrait de malt (5 g par litre) est également sans effet sur la production d'enzymes. Il en est de même pour les sons de blé et d'orge ajoutés directement au milieu sous forme d'infusions, ces dernières tendent plutôt à inhiber la production d'enzymes.

Divers milieux naturels, sensiblement différents du milieu de base, ont été éprouvés :

- lactosérum-présure, déprotéiné par chauffage,

- lactosérum déprotéiné, supplémenté en glucose (10 g par litre) et en extrait de levure ( $2 \mathrm{~g}$ par litre).

- extrait de malt à $30 \mathrm{~g}$ par litre, additionné ou non d'oligoéléments, de trypticase, de glucose, de sels minéraux,

- lait digéré par la papaïne (Guittoneau et Chevalier, 1941), enrichi en éléments minéraux et supplémenté ou non en glucose et extrait de levure.

Le tableau 6 regroupe certains des résultats les plus significatifs.

Le lactosérum, supplémenté ou non, permet un très bon dévelopment du mycélium mais une très faible production d'enzymes. De même le remplacement de la trypticase du milieu de base par de la poudre de lait écrémé à raison de 30 g par litre se traduit par une diminution sensible de l'activité protéasique extracellulaire alors que le poids de mycélium est accru. La moindre production d'enzymes constatée sur ces milieux paraît liée à la nature des sources d'azote et de carbone et à leur concentration mais non à l'acidification, importante en raison du rapport $\mathrm{C} / \mathrm{N}$ élevé, puisque l'addition d'un tampon phosphate ne se traduit pas par une plus forte production.

Les essais de culture sur extrait de malt montrent que, avec ce milieu, la production d'enzymes est pratiquement nulle ; l'addition d'oligo-éléments minéraux n'en améliore pas le potentiel de production, en revanche, avec une addition de trypticase la synthèse des enzymes est notablement accrue.

Le lait papaïné, supplémenté en oligo-éléments minéraux et éventuellement additionné de glucose et d'extrait de levure, est également moins favorable à la production d'enzymes que le milieu Czapektrypticase ; il est pourtant à l'origine d'un développement cellulaire particulièrement actif.

\subsection{Les facteurs de production autres que la composition du milieu de culture}

\subsubsection{TEMPÉRATURE}

La température d'incubation favorable à la production du système protéolytique est comprise entre $15^{\circ} \mathrm{C}$ et $25^{\circ} \mathrm{C}$ en culture non agitée et entre 23 et $25^{\circ} \mathrm{C}$ en culture agitée, avec des valeurs optimales respectives de $22^{\circ} \mathrm{C}$ et $23-25^{\circ} \mathrm{C}$ (tab. 7 ). 


\section{TABLEAU 7}

Influence de la température sur la production du système protéolytique chez $P$. caseicolum*

\begin{tabular}{|c|c|c|c|}
\hline \multirow{3}{*}{$\begin{array}{c}\text { Températures } \\
{ }^{\circ} \mathrm{C}\end{array}$} & \multicolumn{3}{|c|}{ Activité protéolytique } \\
\hline & \multirow{2}{*}{$\begin{array}{l}\text { Cultures } \\
\text { non agitées } \\
\text { (a) }\end{array}$} & \multicolumn{2}{|c|}{ Cultures agitées } \\
\hline & & (a) & (b) \\
\hline 10 & 0 & - & - \\
\hline 15 & 92 & - & - \\
\hline 18 & 92 & 24 & 18 \\
\hline 20 & 100 & 91 & 41 \\
\hline 22 & 110 & 100 & 49 \\
\hline 25 & 90 & 100 & 53 \\
\hline
\end{tabular}

* Conditions des essais :

Souche $P_{1}$, incubation $12 \mathbf{j}$ culture non agitée, $6 \mathbf{j}$ culture agitée ;

Activité exprimée :

(a) en pourcentages de l'activité à la température de référence ;

(b) en p. 100 de l'activité de la culture non agitée.

L'influence de la température sur la vitesse de production en culture agitée montre que la production en $4 \mathrm{j}$ du système protéolytique est maximale à la température de $25^{\circ} \mathrm{C}$ (fig. $6 \mathrm{a}$ ) ; elle décroît d'environ 50 p. 100 quand on s'écarte de cette valeur de plus ou moins $2^{\circ} \mathrm{C}$. Il convient cependant d'observer que si la température de $25^{\circ} \mathrm{C}$ est favorable à une production d'enzymes elle ne se traduit pas par un niveau de production plus élevé après une incubation prolongée (fig. 6 b).

\subsection{2. $\mathrm{pH}$ DU Milieu DE CUlTuRE}

L'influence du $\mathrm{pH}$ du milieu de culture a été déterminée sur des cultures non agitées tamponnées avec un tampon acétate aux $\mathrm{pH}$ inférieurs à 5,5, un tampon phosphate aux $\mathrm{pH}$ supérieurs à 5,0. Le $\mathrm{pH}$ optimal de croissance et de production d'enzymes est compris entre 


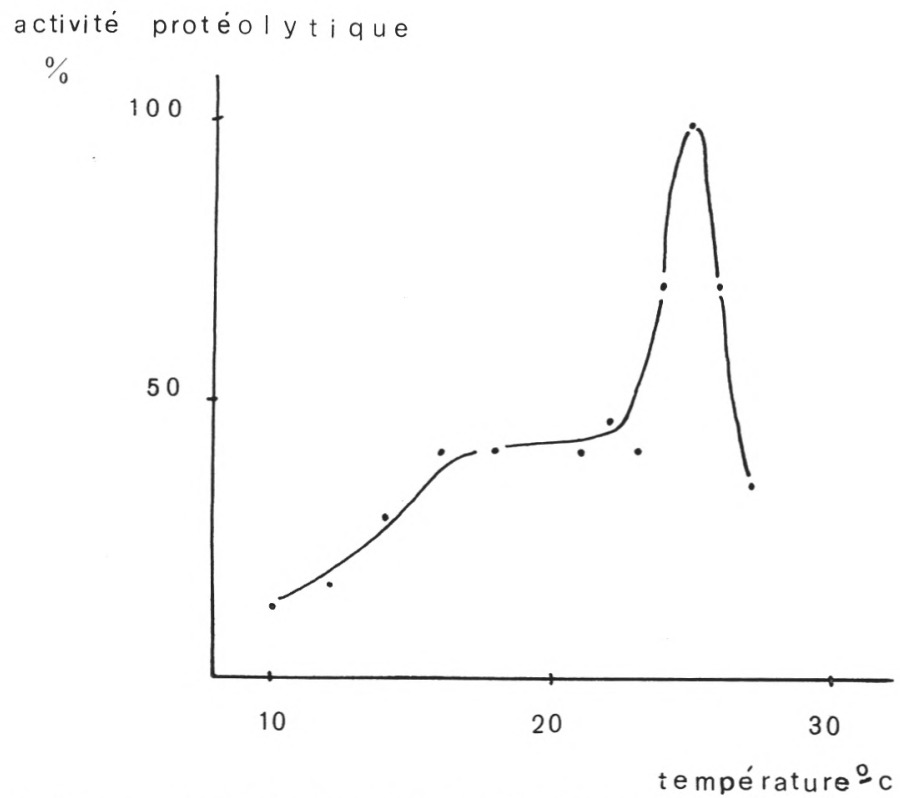

$-6 \mathrm{a}$ : Niveaux de production après $4 \mathrm{j}$ de culture à diverses températures.

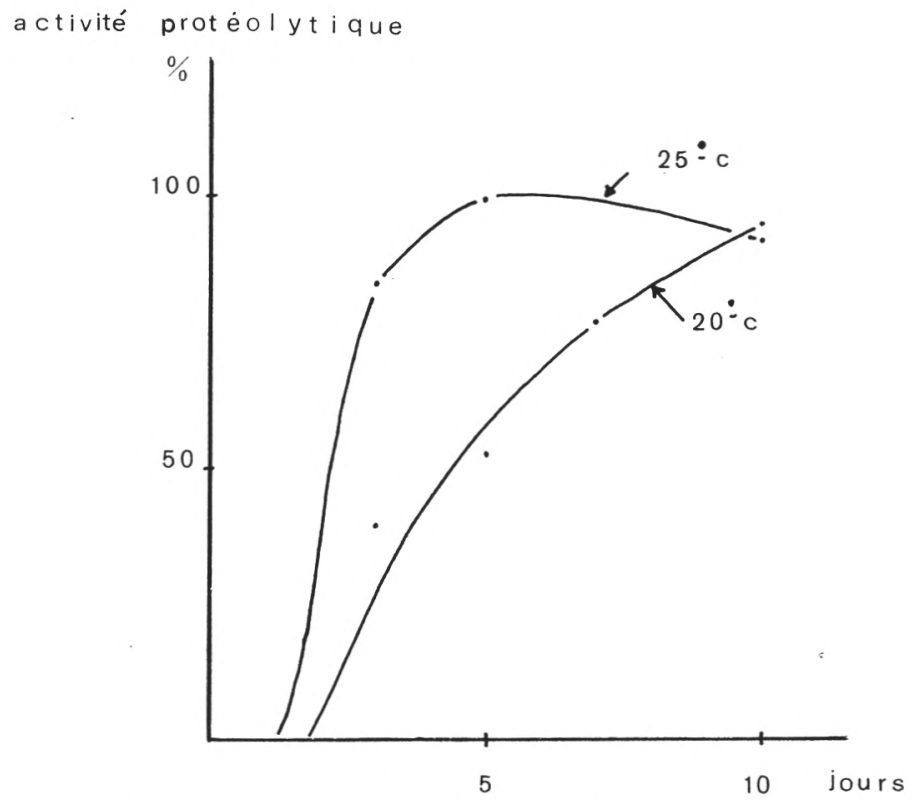

$-6 \mathrm{~b}$ : Vitesses de production comparées à $20^{\circ} \mathrm{C}$ et $25^{\circ} \mathrm{C}$.

fig. 6

Influence de la température de culture sur la vitesse de production du système protéolytique chez $P$. caseicolum

(Souche $\mathrm{P}_{1}$, culture agitée) 
5,5 et 6,5. La même plage de valeur est retrouvée en culture agitée. Aux pH inférieurs, 4,5-5,0, le développement du mycélium et la synthèse des enzymes sont inhibés (tab. 8.).

\section{TABLEAU 8}

Influence du $\mathrm{pH}$ initial du milieu de culture sur la production du système protéolytique chez $P$. caseicolum

\begin{tabular}{|c|c|c|c|c|}
\hline \multirow{2}{*}{$\begin{array}{l}\mathrm{pH} \text { initial } \\
\text { du milieu }\end{array}$} & \multicolumn{3}{|c|}{ Culture non agitée } & \multirow{2}{*}{$\begin{array}{c}\text { Culture agitée } \\
\text { Activité }\end{array}$} \\
\hline & $\begin{array}{c}\mathrm{pH} \\
\text { final }\end{array}$ & $\begin{array}{c}\text { Poids de } \\
\text { mycélium }(\mathrm{g} / \mathrm{l})\end{array}$ & Activité & \\
\hline $\begin{array}{l}4,5 \\
5,0 \\
5,5 \\
6,0 \\
6,5 \\
7,0 \\
7,5 \\
8,0\end{array}$ & $\begin{array}{l}4,5 \\
5,5 \\
6,1 \\
6,1 \\
6,4 \\
6,6 \\
6,9 \\
7,3\end{array}$ & $\begin{array}{c}0 \\
1,2 \\
9,0 \\
9,2 \\
8,5 \\
7,5 \\
6,0 \\
5,0\end{array}$ & $\begin{array}{r}0 \\
20 \\
95 \\
100 \\
92 \\
75 \\
65 \\
55\end{array}$ & $\begin{array}{r}- \\
\overline{1} \\
100 \\
100 \\
75 \\
65 \\
-\end{array}$ \\
\hline
\end{tabular}

Conditions des essais : Souche $\mathrm{P}_{1}$, incubation $20^{\circ} \mathrm{C} 12 \mathrm{j}$ en culture non agitée ; $25^{\circ} \mathrm{C} 6 \mathrm{j}$ en culture agitée.

Activité protéolytique exprimée en pourcentages relatifs.

\subsubsection{Agitation du milieu de culture}

L'influence de l'agitation du milieu de culture a déjà été mise en évidence puisque les différents facteurs de production ont été étudiés en culture agitée et en culture non agitée. Les différences observées se limitent aux facteurs température de culture, nature de la source de carbone et concentration optimale en glucose. Il reste cependant deux points à considérer, l'influence de l'agitation sur le niveau maximal et sur la vitesse de production d'enzymes quand tous les autres facteurs sont identiques.

En ce qui concerne les niveaux de production ceux-ci sont en général plus élevés en culture non agitée. Un exemple est donné dans le tableau 7 consacré à l'influence de la température. Suivant les conditions de culture le rapport des activités maximales en milieu non agité sur celles en milieu agité varie de 2 à 5 . En revanche, la production d'enzymes est plus rapide en culture agitée qu'en culture non agitée ; dans les conditions optimales de température le maximum de 
production est atteint en 6 à $8 \mathrm{j}$ en culture agitée et en 12 à $15 \mathrm{j}$ en culture non agitée (fig. 7).

\subsubsection{TAUX D'ENSEMENCEMENT}

L'importance de l'inocolum ne paraît pas être un facteur déterminant de la croissance et de la production d'enzymes. En culture non agitée, on observe en effet que des variations même très larges dans le taux d'ensemencement (de $10^{2}$ à $10^{5}$ spores par ml de milieu) ne se traduisent pas par des différences appréciables dans le développement du mycélium ou la sécrétion d'enzymes.

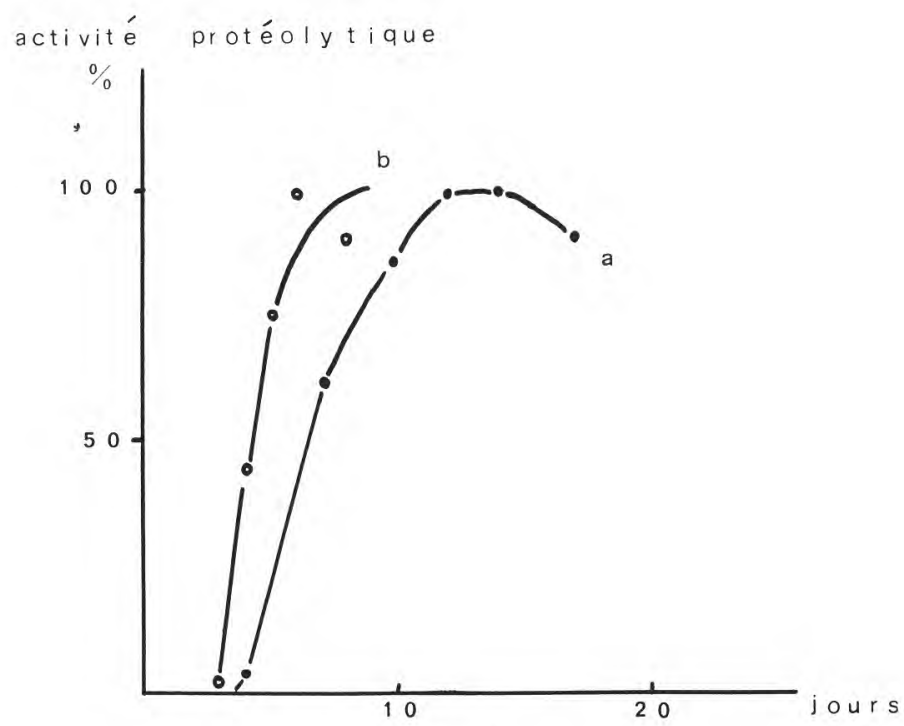

fig. 7

Courbes de production du système protéolytique chez $P$. caseicolum (Souche $\mathrm{P}_{1}$ )

- a : culture non agitée $\left(20^{\circ} \mathrm{C}\right)$.

$-\mathrm{b}$ : culture agitée $\left(25^{\circ} \mathrm{C}\right)$ agitation continue.

La même observation a été faite en culture agitée, avec des inocula de $10^{4}$ à $10^{5}$ spores par ml.

\subsubsection{Mode d'obturation du RÉcipient de culture}

Sur des erlenmeyers de $150 \mathrm{ml}$ contenant $40 \mathrm{ml}$ de milieu de culture, deux modes d'obturation ont été éprouvés, un film plastique de type "parafilm " et le bouchage au coton cardé, ce dernier étant plus ou moins serré.

Avec le bouchage au " parafilm » la culture, non agitée, est maintenue dans un état de semi-anaérobiose et ceci se traduit par une 
modification importante de la physiologie du micro-organisme. On constate en effet que si le développement mycélien est à peine diminué la production d'enzymes extracellulaires est presque totalement inhibée. En ce qui concerne le bouchage coton, le degré de serrage du tampon ne paraît pas influer sur le niveau de la production d'enzymes.

\subsubsection{Production du Système protéolytique EN L'absence de CROISSANCE}

La production du système protéolytique a été essayée en incubant du mycélium lavé dans des conditions impropres à la croissance. Remis en suspension dans de l'eau et incubé pendant $6 \mathrm{~h}$ à $18^{\circ} \mathrm{C}$, le mycélium lavé libère encore une activité protéolytique (tab. 9). Une prolongation de l'incubation ne modifie pas la quantité d'enzymes obtenue. Cette libération n'est pas non plus influencée par la force ionique du milieu de suspension comme le montre l'absence d'effet d'une addition de chlorure de sodium à des concentrations de $0,05 \mathrm{M}$ à $0,8 \mathrm{M}$ (tab. 9). Cependant quand le mycélium est placé en tampon phosphate $0,05 \mathrm{M}$ à $\mathrm{pH}$ 6,5 la quantité d'activité protéolytique libérée est doublée (tab. 9) mais l'addition de $\mathrm{NaCl}$ n'entraîne aucune libéra-

\section{$T A B L E A U 9$}

Libération d'une activité protéolytique par le mycélium lavé de $P$. caseicolum (Souche $P_{1}$ )

\begin{tabular}{|c|c|}
\hline Milieu de suspension & $\begin{array}{l}\text { Activité protéolytique libérée } \\
\text { après } 6 \mathrm{~h} \text { d'incubation à } 18^{\circ} \mathrm{C}^{*}\end{array}$ \\
\hline $\begin{array}{l}\text { Eau distillée } \\
\mathrm{NaCl} 0,05 \mathrm{M} \text { à } 0,8 \mathrm{M}\end{array}$ & $\begin{array}{l}100 \\
100\end{array}$ \\
\hline 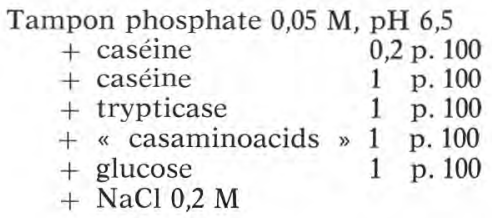 & $\begin{array}{l}210 \\
260 \\
250 \\
155 \\
185 \\
200 \\
210\end{array}$ \\
\hline
\end{tabular}

* Activité exprimée en p. 100 de l'activité libérée dans l'eau distillée.

tion supplémentaire. L'addition au tampon phosphate de composés protéiques ou peptidiques, d'acides aminés ou de glucose a un effet variable, positif ou négatif, mais toujours très limité ; on note au maximum 25 p. 100 de variation par rapport au tampon phosphate 
seul. Ces variations sont trop faibles pour conclure à un effet inducteur sur la synthèse des enzymes protéolytiques.

\subsection{Comportement des différentes souches}

Quatre souches (P1, PL21, PC12, PN14) ayant révélé lors de la mise en place de la collection des aptitudes différentes à la production d'enzymes ont été comparées afin de vérifier si l'influence des principaux facteurs de production établie sur la souche P1 est ou non confirmée avec les autres.

\subsubsection{Composition du MiLieU DE CULTURE}

La nature de la source d'azote paraît être un facteur de production pour lequel sont observés des comportements assez différents.

Ainsi les deux souches P1 et PL21 réagissent comme suit sur milieu contenant diverses peptones.

\begin{tabular}{l|c|c|c|c|c|c}
\hline & $\begin{array}{c}\text { Trypticase } \\
\text { (Mérieux) } \\
\text { témoin }\end{array}$ & $\begin{array}{c}\text { Tryptose } \\
\text { (Difco) }\end{array}$ & $\begin{array}{c}\text { Casitone } \\
\text { (Difco) }\end{array}$ & $\begin{array}{c}\text { Protéose- } \\
\text { peptone } \\
\text { (Difco) }\end{array}$ & $\begin{array}{c}\text { Tryptone } \\
\text { (Difco) }\end{array}$ & $\begin{array}{c}\text { Casamino- } \\
\text { acids } \\
\text { (Difco) }\end{array}$ \\
\hline & 100 & 135 & 160 & 105 & 140 & 60 \\
P 1 & 100 & 50 & 20 & 75 & 145 & 40 \\
PL 21 & & & & & \\
\hline
\end{tabular}

Deux peptones, la tryptose et la casitone, particulièrement favorables à la production d'enzymes avec la souche $\mathrm{P} 1$, le sont beaucoup moins avec la souche PL21.

En revanche, la teneur en azote ne semble pas être à l'origine d'un comportement particulier des souches.

Le remplacement du glucose par une autre source de carbone ne favorise pas la production d'enzymes chez aucune des souches essayées ; l'on note cependant certaines variations comme le montrent les données suivantes :

\begin{tabular}{l|c|c}
\hline & $\begin{array}{c}\text { CT avec glucose } \\
\text { (témoin) }\end{array}$ & CT avec saccharose \\
\hline P 1 & 100 & 30 \\
PN 14 & 100 & 65 \\
\hline
\end{tabular}


L'influence de la teneur en sucre ne diffère pas d'une souche à l'autre et l'on observe chez toutes les souches essayées qu'un taux de $40 \mathrm{~g}$ de glucose en milieu Czapek-trypticase A contenant des phosphates à la concentration $0,1 \mathrm{M}$ permet la production maximale d'enzymes.

\begin{tabular}{l|c|c|c|c}
\hline & P 1 & PL 21 & PC 12 & PN 14 \\
\cline { 2 - 3 } & & & & \\
\hline CT 20 g glucose & 100 & 100 & 100 & 100 \\
CT 40 g glucose & 125 & 110 & 135 & 140 \\
\hline
\end{tabular}

Aucune différence de comportement entre les souches n'est décelée lorsque l'on fait varier le rapport glucose/trypticase du milieu de culture.

En ce qui concerne les besoins minéraux, ont été mis en évidence sur toutes les souches essayées, et ainsi confirmés, la présence indispensable du magnésium, l'intérêt d'une concentration suffisante en phosphate $(0,1$ à $0,2 \mathrm{M})$, l'influence favorable du sulfite et de l'hyposulfite de sodium, l'effet activateur des oligo-éléments (solution A). Il n'a donc pas été observé de différence marquante de comportement.

Les essais de divers milieux ont montré que l'addition d'extrait ou d'autolysat de levure, sans effet sur la production d'enzymes de la souche P1, se traduit, pour d'autres souches, par exemple PN 14, par un accroissement sensible de la production.

\begin{tabular}{l|c|c|c}
\hline & CT témoin & $\begin{array}{c}\text { CT + extrait } \\
\text { de levure } \\
5 \mathrm{~g} / \mathrm{l}\end{array}$ & $\begin{array}{c}\text { CT + autolysat } \\
\text { de levure } \\
5 \mathrm{~g} / \mathrm{l}\end{array}$ \\
\hline P 1 & 100 & 95 & 95 \\
PN 14 & 100 & 120 & 145 \\
\hline
\end{tabular}

En revanche, l'emploi d'autres milieux, tels le lactosérum, supplémenté ou non, le lait papaïné, ou le milieu de Czapek-trypticase enrichi en facteurs de croissance par addition de divers extraits ne permet pas de déceler de différence appréciable entre les souches. 
2.5.2. Facteurs dE PROdUCTION AUTRES QUE LA COMPOSITION DU MILIEU

L'influence de la température de croissance sur le taux de production d'enzymes est variable selon les souches. La température optimale en milieu non agité se situe pour toutes les souches à $20^{\circ} \mathrm{C}-22^{\circ} \mathrm{C}$ mais les écarts observés à $15^{\circ} \mathrm{C}$ et $25^{\circ} \mathrm{C}$ (fig. 8 ) mettent en évidence une nette différence de sensibilité aux variations de température.

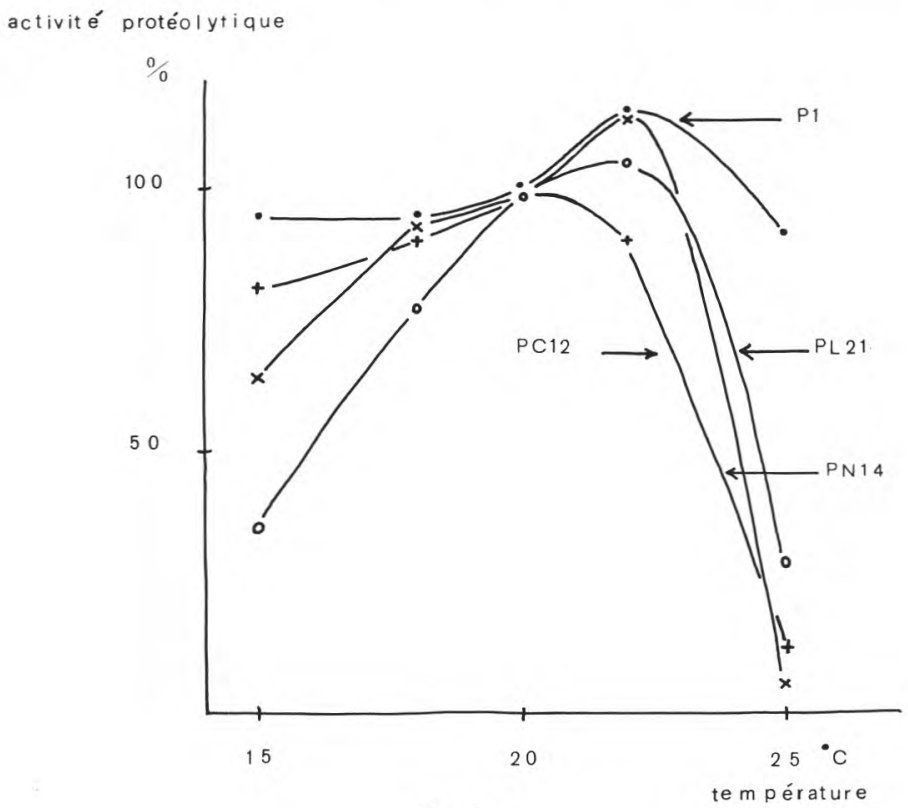

fig. 8

Influence de la température sur la production d'enzymes protéolytiques chez diverses souches de $P$. caseicolum

(cultures non agitées)

L'influence du pH initial du milieu de culture sur la production du système protéolytique est d'une souche à l'autre peu différente ; le pH optimal est de 5,5-6,5 pour toutes les souches, et à $\mathrm{pH} \mathrm{7,5} \mathrm{le}$ taux de production oscille entre 40 et 70 p. 100 de l'optimum.

\begin{tabular}{l|c|c|c|c|c|c}
\hline pH initial & 5,5 & 6,0 & 6,5 & 7,0 & 7,5 & 8,0 \\
\hline & & & & & & \\
\hline & & & & & & \\
P 1 & 95 & 100 & 92 & 75 & 65 & 54 \\
PL 21 & 95 & 100 & 70 & 60 & 40 & 30 \\
\hline
\end{tabular}


Vis-à-vis de l'agitation les quatre souches essayées ont le même comportement. Le niveau maximum de production obtenu en milieu non agité $\left(20^{\circ} \mathrm{C}-12 \mathrm{j}\right)$ est sensiblement plus élevé que celui observé en milieu agité $\left(25^{\circ} \mathrm{C}-8 \mathrm{j}\right)$; toutefois les différences de production en culture agitée et culture non agitée peuvent être d'une souche à l'autre, plus ou moins grandes.

\section{DISCUSSION}

Les facteurs de production de protéases par les champignons ont été le plus souvent étudiés chez des espèces produisant des quantités élevées d'enzymes dans le but d'une production industrielle.

L'étude de ces facteurs se limite alors généralement à la détermination des conditions optimales de culture dans des milieux à base de matériaux bruts d'origine végétale.

Le problème posé íci est très différent. L'examen d'un certain nombre de souches de $P$. caseicolum d'origines diverses n'a pas permis d'isoler des souches fortement productrices de protéases. Une étude attentive des facteurs de production chez cette espèce est donc nécessaire afin de déterminer si la faible productivité résulte de conditions défavorables à la production des enzymes protéolytiques ou d'une caractéristique d'ordre génétique inhérente à l'espèce.

Comme il est de règle générale, la composition optimale du milieu de culture pour la production de protéases diffère notablement de celle pour la production du mycélium ; elle en diffère en particulier par la nature et la concentration de certains constituants, tels les sources de carbone, d'azote et les éléments minéraux.

L'influence de la nature de la source d'azote sur la production de protéase par les champignons peut être variable. Elle peut n'avoir qu'une influence limitée et le choix est alors motivé essentiellement par des considérations d'ordre économique. Dans certains cas, cependant, la présence d'une source d'azote organique, hydrolysat de protéines ou acides aminés, stimule la croissance et la production d'enzymes.

Chez $P$. caseicolum la présence de peptones favorise nettement la production d'enzymes. Ainsi, le taux de production est multiplié par un facteur de 4 à 10 par rapport au milieu nitrate de sodium alors que la croissance n'est multipliée que par un facteur 3 .

La nature de la peptone ne semble pas non plus indifférente. Certaines peptones trypsiques de caséine, comme tryptone et tryptose, exercent une stimulation plus précoce ou plus active. Les peptones d'autres origines, comme soytone, ou préparées selon des techniques différentes, comme casaminoacids, sont beaucoup moins favorables 
à la production d'enzymes. On remarquera cependant que, pour une peptone donnée, le comportement des souches peut être différent.

L'accroissement de la concentration en peptone n'entraîne pas une stimulation supplémentaire de la production d'enzymes bien que la croissance soit plus grande aux taux supérieurs à $10 \mathrm{~g} / \mathrm{l}$; l'alcalinisation du milieu se traduit par une moindre synthèse ou par une inactivation des enzymes.

De nombreux champignons répondent favorablement à la présence d'une source d'azote inorganique. On notera par exemple qu'un milieu nitrate-saccharose-sels minéraux peut être parfaitement suffisant pour la production en fermenteur de la protéase acide de P. janthinellum (Sodek et Hofmann, 1970). Certains micro-organismes semblent même préférer ces sources d'azote, tel est le cas de Aspergillus niger (Ichishima et Yoshida, $1962 \mathrm{a}, 1962$ b). Chez P. caseicolum, il n'en est pas ainsi ; l'on a vu en effet que l'utilisation du nitrate de sodium comme source d'azote se traduit par une réduction sévère de la production du système protéolytique. Il ne semble cependant pas que la production de protéase requière la présence d'une protéine, d'une peptone ou des acides aminés comme il a été rapporté pour une souche de A. niger (Shinmyo et al., 1968) car l'on observe que le sulfate d'ammonium représente une source d'azote presque aussi efficace que la trypticase.

Les diverses sources de carbone ont des effets comparables sur la croissance de $P$. caseicolum mais non sur son aptitude à la production d'enzymes et le glucose est de très loin la source de carbone la plus efficace au plan de cette production. La teneur en sucre influe très nettement sur la croissance et dans certaines limites le poids de mycélium est proportionnel au taux de sucre assimilable. La production de protéases n'obéit pas à la même loi : l'optimum de production correspond à des teneurs en glucose de 20 à $40 \mathrm{~g} / \mathrm{l}$. On remarquera à ce propos qu'il est possible d'augmenter notablement la teneur en sucre du milieu sans qu'il y ait acidification excessive; l'accroissement de la teneur en azote se traduit, en revanche, par une alcalinisation beaucoup plus nette. Ce phénomène pourrait être dû à une faible aptitude de $P$. caseicolum à la production d'acides organiques comparée à sa forte activité désaminasique, mais il est plus probablement lié au pouvoir tampon du phosphate, beaucoup plus important dans la zone de $\mathrm{pH}$ 6-7 que dans l'intervalle 7-8. D'ailleurs, les résultats obtenus montrent clairement qu'au plan de la production enzymatique, les teneurs en sources de carbone et d'azote ne peuvent varier indépendamment l'une de l'autre. Par une valeur judicieuse du rapport $\mathrm{C} / \mathrm{N}$ il importe en effet de maintenir le $\mathrm{pH}$ des cultures dans des limites favorables à la croissance et à la production d'enzymes. Ainsi, l'effet défavorable d'une forte concentration en azote peut être en partie compensé par des taux de glucose suffisamment élevés pour maintenir le $\mathrm{pH}$ au voisinage de 7 . On notera cependant que même dans ces conditions 
l'accroissement du taux d'azote ne se traduit pas par une production enzymatique plus active.

Les éléments minéraux jouent un rôle important sur le développement des champignons et la production d'enzymes, mais ce facteur n'a pas la même incidence sur les deux phénomènes. Ainsi, une étude très complète de Steiner (1961) de l'effet des oligo-éléments sur Aspergillus oryzae a mis en évidence que la concentration optimale pour la production d'enzymes est supérieure à celle exigée pour la croissance. Une observation analogue est faite ici chez $P$. caseicolum, la production des protéases est multipliée par plus de 2 avec $1 \mathrm{ml}$ de la solution d'oligo-éléments $\mathrm{A}$, par plus de 3 avec $10 \mathrm{ml}$ de cette même solution.

La production des enzymes chez $P$. caseicolum est également très sensible à l'ion $\mathrm{Mg}$. En son absence elle est presque totalement inhibée bien que la croissance reste proche de la normale. Une telle influence du magnésium avait été antérieurement mise en évidence chez Alternaria tenuissima (Jonsson et Martin, 1965) et Aspergillus fumigatus (Jonsson et Martin, 1964), mais non chez Aspergillus oryzae (Steiner, 1961).

L'on notera également l'influence favorable sur la sécrétion d'enzymes de certaines formes de soufre minéral, hyposulfite et sulfite par exemple, alors que les sulfates sont sans effet.

L'intérêt, au plan de la production d'enzymes, d'une concentration suffisante en phosphates mérite une mention particulière car l'action de ces sels peut être due au maintien du $\mathrm{pH}$ à une valeur convenable, au facteur nutritionnel ou à la création d'une force ionique suffisante. Ce dernier mode d'intervention est peu probable car si dans le genre Mucor la production optimale de protéases exige l'addition au milieu de culture d'une concentration élevée $(0,5 \mathrm{M})$ de $\mathrm{NaCl}$ ou d'un autre sel mono ou divalent (Somkuti et Babel, 1969 ; Wang, 1967), cet effet, dû à la libération de l'enzyme qui, autrement, reste accrochée au mycélium, n'a pas été retrouvée chez $P$. caseicolum, ni dans le milieu de culture, ni lors du traitement d'une suspension de mycélium au cours duquel le phosphate a également un effet favorable sur la libération de protéases.

Les facteurs de croissance ont un effet nul ou très limité sur la production d'enzymes chez $P$. caseicolum. Le milieu de base utilisé dans notre expérimentation paraît donc satisfaire tous les besoins de la moisissure. Cette hypothèse se trouve confirmée par les résultats obtenus à partir d'autres milieux de culture dont aucun ne permet une production plus satisfaisante. Tel est le cas, par exemple, d'un milieu naturel riche en oligo-éléments, peptides et facteurs de croissance comme le lait papaïné supplémenté ; bien qu'il permette une croissance double de celle obtenue sur Czapek-trypticase, il n'assure que 50 p. 100 de la production d'enzymes observée sur ce milieu. 
On peut noter également que le lactosérum, même après supplémentation, est un très mauvais milieu pour la production des protéases. Ce phénomène paraît lié, non à la nature de la source de carbone, mais plutôt à l'absence des acides aminés nécessaires à la synthèse enzymatique ou d'inducteurs comme tendent à le montrer les résultats obtenus à partir du lait papaïné.

L'étude des facteurs relevant de la composition du milieu de culture montre finalement que le milieu Czapek-trypticase A (CT) permet une production proche de l'optimum. Celle-ci en effet ne peut être accrue que d'une façon très limitée par addition de certaines formes de soufre, accroissement de la teneur en magnésium, de la concentration en phosphates ou du rapport $\mathrm{C} / \mathrm{N}$, supplémentation en autolysat de levure et oligo-éléments. En associant ces divers éléments favorables on obtient un milieu CT modifié dont le potentiel de production d'enzymes est sensiblement plus élevé que celui du milieu témoin (tab. 10) sans pour autant qu'il y ait effet cumulatif des différents facteurs.

L'étude des facteurs autres que la composition du milieu de culture n'apporte guère de possibilités d'améliorer la production de protéases par rapport aux conditions choisies lors de la caractérisation de l'espèce.

\section{TABLEAU 10}

Production d'enzymes protéolytiques sur milieu Czapek-trypticase A (CT) et sur milieu CT modifié*

\begin{tabular}{l|c|c}
\hline & \multicolumn{2}{|c}{ Activité protéolytique sur } \\
\cline { 2 - 3 } Souches & CT témoin & CT modifié \\
\hline & & 135 \\
P 1 & 100 & 150 \\
PN 14 & 100 & 165 \\
PE 1 & 100 & 195 \\
PN 28 & 100 & \\
\hline
\end{tabular}

* Conditions des essais : incubation $20^{\circ} \mathrm{C}, 15 \mathrm{j}$, culture non agitée. Activité protéolytique exprimée en pourcentages relatifs.

Composition du milieu CT modifié : glucose $40 \mathrm{~g}$; trypticase $10 \mathrm{~g} ; \mathrm{KCl} 0,5 \mathrm{~g}$; Fe $\mathrm{SO}_{4}, 7 \mathrm{H}_{2} \mathrm{O} 0,01 \mathrm{~g} ; \mathrm{Mg} \mathrm{SO}, 7 \mathrm{H}_{2} \mathrm{O} 1 \mathrm{~g} ; \mathrm{Na}_{2} \mathrm{SO}_{3} 1 \mathrm{~g}$; autolysat de levure $5 \mathrm{~g}$; tampon phosphate $\mathrm{pH} 6,50,4 \mathrm{M} 500 \mathrm{ml}$; solutions d'oligo-éléments A $10 \mathrm{ml}$ et B $10 \mathrm{ml}$; eau distillée $500 \mathrm{ml}$. 
Les températures favorables sont celles rencontrées généralement chez les champignons ; en revanche, le $\mathrm{pH}$ de 5,5-6,5, optimal pour la synthèse enzymatique, est sensiblement supérieur à celui trouvé chez des espèces voisines, 4,9 par exemple chez $P$. camemberti (Dolezalek et Minarik, 1968).

Le plus faible niveau de production obtenu en culture agitée peut avoir plusieurs causes; soit une aération trop forte - chez Alternaria tenuissima l'influence défavorable d'une telle aération en culture submergée a été observée (Jonsson et Martin, 1965) — soit une différence dans la composition de l'atmosphère située au-dessus de la culture, en particulier une différence dans la teneur en $\mathrm{CO}_{2}$.

On notera finalement que Penicillium caseicolum a, comparativement à de nombreux autres champignons, une aptitude à la production d'enzymes protéolytiques relativement faible, pas seulement par le niveau de production mais aussi par la vitesse, même en culture agitée, car en général le maximum est alors atteint en 3 à 4 j (Jonsson et Martin, 1964).

\section{$R$ é $s$ u mé}

Après avoir précisé les caractères du système protéolytique de $P$. caseicolum, l'étude des facteurs qui en contrôlent la production a été réalisée.

Au plan de la composition du milieu, les peptones, en particulier les peptones trypsiques, et le glucose semblent être les sources d'azote et de carbone les plus efficaces pour un rapport carbone/azote judicieux. L'effet favorable des éléments minéraux, en particulier de l'ion $\mathrm{Mg}$, de quelques oligo-éléments ainsi que de certaines formes de soufre est noté. L'intérêt d'une concentration suffisante en phosphates est également discuté.

Pour les autres facteurs, notamment la température et le $\mathrm{pH}$, les conditions optimales de la production d'enzymes sont les suivantes : température $22^{\circ} \mathrm{C}-25^{\circ} \mathrm{C}$, pH 5,5-6,5. L'agitation du milieu entraîne un accroissement de la vitesse de production mais elle tend à en diminuer le niveau.

L'aptitude de $P$. caseicolum à la production d'enzymes protéolytiques est relativement faible comparée à celle de nombreux autres champignons. L'étude des facteurs de cette production montre qu'il est difficile de l'accroître dans des proportions importantes.

\section{Su m mary}

After having specified the characteristics of the proteolytic system of $P$. caseicolum, the study of the factors which control its synthesis has been carried out. 
Concerning the composition peptones, especially trypsic peptones, and glucose seem to be the most efficient supply in nitrogen and $\mathrm{C}$

carbon, when a convenient $\frac{\mathrm{C}}{\mathrm{N}}$ ratio is choosen. Salts, especially $\mathrm{Mg}++$ ion, some oligo-elements and some forms of sulfur exhibit a noticiable effect on enzyme production. The advantage of having a sufficient concentration in phosphates is also discussed.

Concerning the other production factors, especially temperature and $\mathrm{pH}$, the optimum conditions for the enzyme production are the following : temperature : $22^{\circ} \mathrm{C}-25^{\circ} \mathrm{C}$ and $\mathrm{pH} 5,5-6,5$. The shaking of the medium increases the production rate but reduces the final amount produced.

The ability of $P$. caseicolum in producing proteolytic enzymes is rather low when it is compared to that of many other fungi. The study of its production factors shows that it is not easy to improve its level in substantial proportions.

Reçu pour publication le 10 janvier 1973.

\section{Références bibliographiques}

ANson (M. L.) (1938), - The estimation of pepsin, trypsin, papaïn and cathepsin with hemoglobin. J. Gen. Physiol., 22, 79.

Bank (G. T.), BinNs (F.) and Cutclifee (R. L.) (1967). - Recent developments in the production and industrial applications of amylolytic enzymes derived from filamentous fungi. In progress in industrial microbiology, vol. 6, 95-139, Heywood Hockenhull (D.J.D., Books, London.

DAviEs (R.) (1963). - Microbial extracellular enzymes, their uses and some factors affecting their formation. In Rainbow (C.), Rose (A. H.), Biochemistry of Industrial micro-organisms, 68-150, Academic Press, New-York.

Dolezalek (J.) (1956). - Etude biochimique de Penicillium caseicolum. Industr. Alim. Agric., 73, (7-8), 535-539.

Dolezalek (J.) et MinaRik (R.) (1968). - Influence du milieu et de la présure sur l'activité enzymatique de Penicillium camemberti et Penicillium nalgiovensis. Sb. vys. Sk. Chem. Technol. Prazé, Potravin. Technol., E. $20,67$.

Folin (O.) and Ciocalteu (V.) (1927). - On tyrosine and tryptophane determination in proteins. J. Biol. Chem., 73, 627.

Guittonneau (G.) et Chevalier (R.) (1941). - Nouvelles techniques de préparation d'un milieu de culture à base de lait digéré. Le lait digéré par la papaïne. Le Lait, 21, (201-203), 1-8.

Ichishima (E.) and Yoshida (F,) (1962 a). - Studies on proteolytic enzymes of black Aspergilli. Part VII. Effect of inorganic nitrogen compounds for the production of acid protease by Kuro-Koji mold group in solid cultivation. Agr. Biol. Chem., 26, 547.

Ichishima (E.) and Yoshida (F.) (1962 b). - Studies on proteolytic enzymes of black Aspergilli. Part VIII. Effect of inorganic nitrogen compounds for the production of acid protease by Kuro-Koji mold group in submerged cultivation. Agr. Biol. Chem., 26, 554. 
Jonsson (A. G.) and Martin (S. M.) (1964). - Protease production by Aspergillus fumigatus. Agr. Biol. Chem., 28, 734-739.

Jonsson (A. G.) and MARTIN (S. M.) (1965). - Protease production by Alternaria tenuissima. Agr. Biol. Chem., 29, 787-791.

Kunitz (1947). - Crystalline soybean trypsin inhibitor. J. Gen. Physiol., 30, 291.

Lenoir (J.), Veisseyre (R.), Hermier (J.), Mocouot (G.), Bret (G.), Galzin (M.) et ARDIN (F.) (1971), - Les enzymes d'origine microbienne et leur emploi dans l'affinage des fromages. Le Lait, 51, (503-504), 135-137.

Lenorr (J.) et Choisy (C.) (1971). - Aptitude de l'espèce Penicillium caseicolum à la production d'enzymes protéolytiques. Le Lait, 51, (503-504), 138-157.

Maze (P.) (1905). - Les microbes dans l'industrie fromagère. Ann. Inst. Pasteur, Paris, 19, 378-403, 481-493.

Meyers (E.) and KNight (S. G.) (1958). - Studies on the nutrition of Penicillium roqueforti. Appl. Microbiol., 6, (3), 174-178.

Sansonnetti (F.) (1930). - Sur les flores bactériennes et fongiques des caillés de lait. Le Lait, 10, 627.

Sekin (K.), Nasumo (S.) and Iguchi (N.) (1969), - Aspergillus sojae. Agric. Biol. Chem., 33, 1477.

Shinmyo (A.), Okazaki (M.) and Terui (G.) (1968). - Kinetic studies on enzyme production by microbes. Some physiological basis for kinetic studies on acid protease production by Aspergillus niger. J. Ferment. Technol., 46, 733-742.

SoDEK (J.) and Hofmann (T.) (1970). - Large-scale preparation and some properties of penicillo-pepsin, the acid proteinase of Penicillium janthinellum. Can. J. Biochem., 48, 425-431.

Somkuti (G. A.) and Babel (F. J.) (1969). - Production of Mucor pusillus acid protease in reconstituted whey. J. Dairy Sci., 52, 535-536.

STEINER (K.) (1961). - Uber den Einfluss von Spurenelementen auf Wachstum und Enzym-bildung von Aspergillus oryzae (Ahlburg). Cohn. Zentr. Bakteriol. Parasitenk., Abt., II, 114, 47-106.

Тном (C.) (1906). - Fungi in cheese ripening : Camembert and Roquefort. U.S. Dept. Agric. Bur. Anim. Ind. Bull., 82, 1-39.

Тном (C.) (1909). - Camembert cheese problems in the United States. U.S. Dept. Agr. Bur. Anim. Ind. Bull., 115, 1-54.

Thom (C.), and RAPER (K.) (1945). - A manual of the Aspergilli. Williams and Wilking co, Baltimore.

Tsugo (T.) and Matsuoka (H.) (1963). - Studies on the manufacture of semi soft white mould cheese ripened by Penicillium caseicolum. II. Qualities of proteases produced by $P$. caseicolum. Jap. J. Zoot. Sci., 33, (6), 480-483. In Dairy Sci. Abstr., 25, 1749).

WANG (H. L.) (1967), - Release of proteinase from mycelium of Mucor hiemalis. J. Bacteriol., 93, 1794-1799. 